\title{
SOEP
}

SOEPpapers
on Multidisctilinary Panel Data Research

SOEPnaNors
on Multidisciplinary Panel Data Research

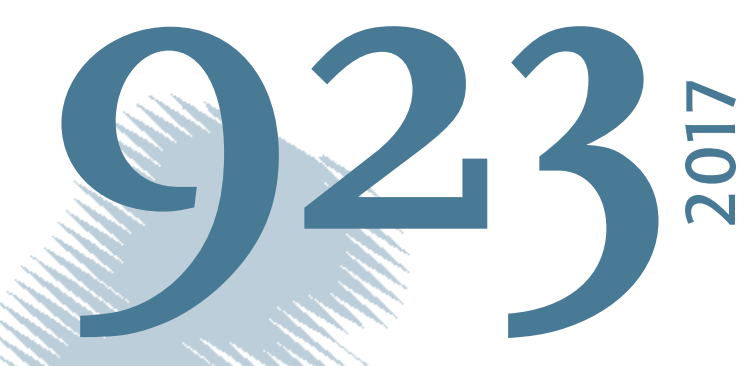

\section{Taxing Childcare: Effects on Childcare Choices, Family Labor Supply and Children}


This series presents research findings based either directly on data from the German SocioEconomic Panel study (SOEP) or using SOEP data as part of an internationally comparable data set (e.g. CNEF, ECHP, LIS, LWS, CHER/PACO). SOEP is a truly multidisciplinary household panel study covering a wide range of social and behavioral sciences: economics, sociology, psychology, survey methodology, econometrics and applied statistics, educational science, political science, public health, behavioral genetics, demography, geography, and sport science.

The decision to publish a submission in SOEPpapers is made by a board of editors chosen by the DIW Berlin to represent the wide range of disciplines covered by SOEP. There is no external referee process and papers are either accepted or rejected without revision. Papers appear in this series as works in progress and may also appear elsewhere. They often represent preliminary studies and are circulated to encourage discussion. Citation of such a paper should account for its provisional character. A revised version may be requested from the author directly.

Any opinions expressed in this series are those of the author(s) and not those of DIW Berlin. Research disseminated by DIW Berlin may include views on public policy issues, but the institute itself takes no institutional policy positions.

The SOEPpapers are available at http://www.diw.de/soeppapers

\section{Editors:}

Jan Goebel (Spatial Economics)

Martin Kroh (Political Science, Survey Methodology)

Carsten Schröder (Public Economics)

Jürgen Schupp (Sociology)

Conchita D'Ambrosio (Public Economics, DIW Research Fellow)

Denis Gerstorf (Psychology, DIW Research Director)

Elke Holst (Gender Studies, DIW Research Director)

Frauke Kreuter (Survey Methodology, DIW Research Fellow)

Frieder R. Lang (Psychology, DIW Research Fellow)

Jörg-Peter Schräpler (Survey Methodology, DIW Research Fellow)

Thomas Siedler (Empirical Economics, DIW Research Fellow)

C. Katharina Spieß (Education and Family Economics)

Gert G. Wagner (Social Sciences)

ISSN: 1864-6689 (online)

German Socio-Economic Panel (SOEP)

DIW Berlin

Mohrenstrasse 58

10117 Berlin, Germany

Contact: soeppapers@diw.de

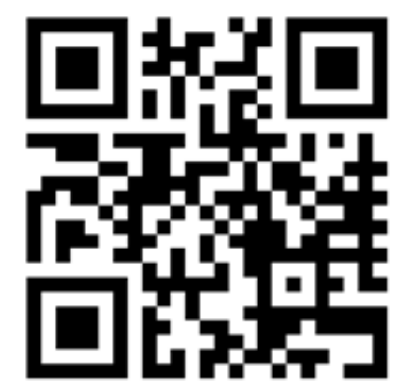




\title{
Taxing Childcare:
}

\section{Effects on Childcare Choices, Family Labor Supply and Children}

\author{
Christina Gathmann and Björn Sass
}

July 21, 2017

\begin{abstract}
Previous studies report a range of estimates for the response of female labor supply and childcare attendance to childcare prices. We shed new light on these questions using a policy reform that raises the price of public daycare. After the reform, children are 8 percentage points less likely to attend public daycare which implies a compensated price elasticity of -0.6. There is little labor supply response in the full sample, though declines for vulnerable subgroups. Spillover effects on older siblings and fertility decisions show that the policy affects the whole household, not just targeted family members.
\end{abstract}

Acknowledgments: We thank Iwan Barankay, Thiess Buettner, Janet Currie, Ronny Freier, Nabanita Datta Gupta, Peter Haan, Eckhard Janeba, Takao Kato, David Ribar, Regina Riphahn, Klaus Schmidt, Uta Schönberg, Thomas Siedler, Katharina Spiess, Michele Tertilt, Elu von Thadden, Matthias Wrede, Katharina Wrohlich and seminar participants at Aarhus Business School, DIW Berlin, University of Darmstadt, Dresden, Mannheim, Nürnberg-Erlangen, Aalto University in Helsinki and the Workshop on Natural Experiments and Controlled Field Studies in Holzhausen for helpful comments. We are grateful to the staff at GESIS in Mannheim, the Statistical Office of Germany for their help with the Micro Census and the DIW for their help with the SocioEconomic Panel (SOEP). Benjamin Bruns and Christoph Esslinger provided outstanding research assistance. We are responsible for all remaining errors.

Corresponding author: Christina Gathmann, Department of Economics, University of Heidelberg, IZA and CESifo, christina.gathmann@awi.uni-heidelberg.de., Björn Sass, bjoern.sass@absolventum.uni-mannheim.de. 


\section{Introduction}

Female labor supply has increased dramatically in many countries over the past decades (Jaumotte 2003; Boeri 2005). Employment among women in Germany or Portugal, for example, has increased from less than $50 \%$ in 1981 to over $70 \%$ in 2001 . And yet, there remain large crosscountry differences in female employment. While female labor force participation is above $80 \%$ in Scandinavian countries, it is only about $60 \%$ in Southern Europe like Italy or Spain. Many view generous child care policies as a key determinant of both the observed cross-country differences (Jaumotte 2003) and the dramatic growth of female employment over the last decades (Attanasio et al. 2008). Proponents of such policies argue that affordable childcare is crucial to encourage female labor force participation and promote economic self-sufficiency, especially among single parents. Pundits, in contrast, think that childcare subsidies distort the allocation of resources and may have negative consequences for child development.

We make use of a recent policy reform in East Germany to provide new evidence on this important debate about public daycare, maternal labor supply and child development. In 2006, the government of one East German state (Thuringia) introduced a new family policy that provides generous subsidies to families that do not send their 2 year-old child to public daycare ("home care subsidy"). ${ }^{1}$ The size of the monthly subsidy is substantial: it pays 150 euros if the eligible child is the firstborn and up to 300 euros if the 2 year old is the fourth- or higherorder child. The subsidy is almost twice as large as the average monthly childcare fee in 2006, and contributes a non-trivial share (of about 10\%) to the disposable income of East German families with small children. The structure of the subsidy is such that it declines linearly with the number of hours the eligible child attends daycare. Theoretically, the subsidy is equivalent to an increase in the hourly price of public childcare which is fully compensated by an income subsidy. As a consequence, families using public childcare can buy the same bundle of goods as before the reform. Yet, they might not choose to do so because public childcare has become more expensive relative to other childcare choices. Families who did not plan to use public childcare even before the reform (and hence, do not face higher childcare costs) still receive an additional transfer of at least 150 euros per month after the reform.

The policy reform generates rare exogenous variation in childcare prices in a setting where public daycare is widely available, a relic of East Germany's socialist past. Using this variation, we provide a comprehensive analysis how the reform affects childcare choices, family labor

\footnotetext{
${ }^{1}$ In what follows, we label daycare that is publicly subsidized public daycare. In East Germany, most publicly subsidized daycare facilities are provided by the municipality. Some facilities are operated by the Catholic or Protestant churches or other non-profit organizations; for-profit childcare facilities that do not obtain public subsidies are rare.
} 
supply, short-run child development and siblings in the family. Our findings have important lessons for policy makers, especially because the federal government introduced a similar subsidy in all of Germany in 2013. Beyond the particular empirical setting, our analysis provides valuable insights into the relationship between childcare costs and family choices for very young children. We thus view our analysis as a complement to earlier studies analyzing the availability of childcare or effects for older preschool children.

We have five main findings. First, parents respond to the compensated price increase of daycare by reducing daycare attendance of eligible children by 8 percentage points. The additional income also results in an even stronger decline in informal care provided by friends, relatives and neighbors. Instead, eligible children are now more likely to be cared for exclusively at home. Our estimates imply a compensated price elasticity of public daycare of about -0.6 . Second, on the labor supply side, we find few immediate effects though mothers seem to postpone their re-entry into the labor market. Our estimates imply an elasticity of labor force participation with respect to childcare costs in the range of -0.1 to -0.2 which is similar to other studies using quasi-experimental evidence.

Third, we find that boys benefit in the short-run from the policy in terms of their cognitive and non-cognitive skills while girls do not. The main reason for this gender difference is that parents of boys switch from informal care to home care when the home care subsidy is introduced. Parents of girls in contrast, hardly adjust their mode of childcare after the reform. As a result, boys benefit from higher-quality care at home, while girls do not benefit from the typically lower-quality informal care they receive. Below, we discuss a number of potential explanations for this gender-specific response of parents.

Fourth, we find even stronger responses for economically vulnerable families. Single and low-income parents mainly use the additional income to switch from informal care to home care. Children benefit from this switch in terms of their short-run skills. Low-skilled parents in contrast, are much more likely to take their child out of public daycare and use informal care arrangements instead. In this group, informal and public daycare appear to be substitutes. That low-skilled parents are less likely to send their child to public daycare is bad news for these children's cognitive and non-cognitive development - a situation we know is difficult to compensate later in life (Almond and Currie 2011; Heckman 2006). In contrast to the full sample, female labor force participation declines substantially for vulnerable families after the home care subsidy is introduced. This decline is likely to reduce economic self-sufficiency among vulnerable families as second earners often supplement family income or compensate an unemployment spell of the first earner. 
Fifth, we document that the new policy affects the whole family, not just eligible children and their mothers. The new subsidy has effects on fertility and older siblings in eligible households. Older preschool siblings, for example, are much more likely to be cared for at home after the reform; one potential explanation is that parents supervise older siblings together with eligible children. Our results highlight that evaluations of family policies need to take into account adjustments for all members in the household.

Our empirical analysis uses a difference-in-differences strategy which compares families with eligible children in the treatment state to other East German states before and after the introduction of the policy in 2006. We perform a range of informal specification checks whether the assumption of parallel state trends is valid: we show that different specifications for state trends does not affect the results. In addition, we run placebo tests with hypothetical reforms in pre-reform years. Furthermore, we employ a triple differences strategy using older preschool children as an additional control group to eliminate state-specific common trends. We also implement a semi-parametric difference-in-differences estimator which reweighs observations in order to make families in the treatment and control states more similar in their observable characteristics. None of these alternative empirical tests change our qualitative conclusions. We report a number of additional tests to rule out that changes in preferences or other state-specific changes explain our results. Finally, we present a range of estimators to correct standard errors as the treatment occurs in a single state.

\section{Related Literature}

Closest to our analysis is a small literature on the introduction of home care (or cash for care) subsidies in other European countries (see Schøne 2004; Naz 2004; Kornstad and Thoresen 2007; Bettinger et al. 2014 for Norway; Kosonen 2014 for Finland; and Piketty 2005 for France). All of these reforms were implemented at the national level, which makes it difficult to separate the reform effect from changes in the economic and social environment that also affect labor supply. Kosonen (2014) exploits supplements to the national subsidy that vary across municipalities in Finland. He finds that a subsidy increase by 100 euros reduces maternal labor supply by 3 percentage points but has no effect on paternal employment. ${ }^{2}$

More generally, our work relates to the long-standing question how childcare costs affect female labor supply (starting with Heckman 1974). An older literature analyzed labor supply

\footnotetext{
${ }^{2}$ Bettinger et al. (2014) in turn use variation in age of eligibility and year to study the educational outcomes of older siblings. Like us, they find substantial spillover effects of the cash for care subsidy on siblings of eligible children. Our analysis focuses however, on the immediate effects of the cash for care subsidy on eligible children and their families.
} 
responses to childcare costs (Anderson and Levine see e.g. 2000; Connelly see e.g. 1992; Kimmel see e.g. 1995; Ribar see e.g. 1992). Identifying a causal effect of childcare costs on female labor supply is challenging here as parents choose the facility and hence childcare expenses. It is therefore not too surprising that estimates of labor supply elasticities differ widely ranging from 0 to smaller than -1 (see Blau and Currie, 2006 for a survey). A few recent studies have exploited changes in childcare subsidies as exogenous source of variation. The results seem to suggest modest responses if at all. While a decline in childcare prices has little effect on female labor supply in Sweden (Lundin et al. 2008; Brink et al. 2007), low-income mothers in the United States show a modest response with estimated elasticities ranging from -0.1 to -0.3 (Blau and Tekin 2007).

A growing literature has studied how the availability of public childcare for preschool children shifts maternal labor supply (see Berlinski et al. 2009 for Argentina; Cascio 2009; Gelbach 2002 for the United States; Lefebvre and Merrigan 2008 for Canada; Havnes and Mogstad 2011b for Norway; and Chiuri 2000 for Italy). The results are again not clear-cut. Havnes and Mogstad (2011b) and Fitzpatrick (2010) find little impact on parental employment from an expansion of publicly provided childcare in Norway and the US respectively. In contrast, Goux and Maurin (2010) show that daycare among 2-3 year-old children increases the labor supply in single earner families in France. Similarly, Nollenberger and Rodríguez-Planas (2015) find that universal childcare for 3 year-old children increases maternal labor supply. As childcare is widely available in our setting, this paper focuses on responses to childcare prices rather than its availability. Expanding the number of childcare slots in an area is likely to generate a slower, but possibly larger response than a change in prices. At the same time, childcare costs is an increasingly important margin of adjustment as childcare has become more widely available in many countries. Another difference of our study is that we focus on the consequences of childcare for very young children (age 2) for which there is much less evidence than for older pre-school children.

We also touch on a growing economic literature how maternal employment and non-parental childcare affect child development (see Almond and Currie 2011 for a survey). Given that the policy has been introduced very recently, we focus on the short-run consequences for child development here. Earlier studies suggest that maternal employment in the first year is associated with lower verbal and math test scores though the results are not always robust (Anderson and Levine 2000; Baum 2003; Berger et al. 2005; Blau and Grossberg 1992; Ruhm 2004; Waldfogel et al. 2002). ${ }^{3}$ After a child's first birthday, the effects of non-parental childcare appear to be

\footnotetext{
${ }^{3}$ Maternal employment seems to have negative effects for children's health as measured by their weight as well; most of the detrimental effects are concentrated in high-income families though (Anderson et al. 2003).
} 
negligible or even positive (see e.g. James-Burdumy 2005). One empirical challenge here is that mothers who return to work very early after giving birth might differ from mothers who do not along unobservable dimensions. As such, it is difficult to separate the effects of non-parental care from other circumstances that may slow down child development. Recently, several studies have used extensions in maternity leave policies or the expansion of public daycare to study how changes in labor supply and childcare choices affect children. Most studies find few short-run effects of maternity leave extensions (Baker and Milligan 2010); yet, negative effects were found for children of low-income mothers who increased their labor force attachment following the 1996 welfare reform (Bernal and Keane 2011). ${ }^{4}$ One reason previous studies have found conflicting results could be that the counterfactual scenario is not always clear: the consequences of maternal employment for child development early in life might be very different if the child goes to a high-quality daycare than if it goes to an informal care arrangement. While informal care seems to have negative consequences for child development (Herbst 2013), public daycare attendance has no negative or even positive effects, especially for disadvantaged children (e.g. Currie and Thomas 1995, 1999; Datta-Gupta and Simonsen 2010; Felfe and Lalive 2017; Dustmann et al. 2015).

Closest to us is the study of a comprehensive childcare reform in Canada which decreased childcare prices and expanded childcare availability (Baker et al. 2008; Lefebvre and Merrigan 2008). The reform mainly affected middle-income families because low-income families were eligible for the childcare subsidies even prior to the reform. The authors find substantial labor supply responses both at the extensive and intensive margin. Baker et al. (2008) also report some negative effects for child development. ${ }^{5}$ More recently, Kottelenberg and Lehrer (2017) show that the universal childcare program benefited children from disadvantaged backgrounds.

Our setting however, differs from the Canadian context along several dimensions: the reform in East Germany was a price increase compensated by an income transfer with few changes on the supply side. In addition, the reform we analyze affected all families in the reform state. We can thus estimate the elasticity of childcare choices with respect to childcare costs for the average family, for example, as well as for economically vulnerable subgroups.

\footnotetext{
${ }^{4}$ There is also an emerging literature studying long-term consequences for child development (see e.g. Carneiro et al. 2015; Dustmann and Schönberg 2012; Havnes and Mogstad 2011b for examples).

${ }^{5}$ Due to the large-scale expansion, the quality of care seemed to have suffered in some newly established facilities. A decline in care quality could be one potential explanation for the documented negative effects on child development.
} 


\section{Institutional Background}

\subsection{Public Childcare in Germany}

To facilitate the interpretation of our findings, we first describe the provision of public childcare for preschool children in Germany. Most childcare facilities are operated by municipalities or private non-profit agencies. Only about $1.6 \%$ of preschool children and $2 \%$ of children under age 3 attend a daycare supplied by a private, for-profit provider (Muehler 2009). The supply of childcare has traditionally been much higher in East than in West Germany, a legacy of its socialist past. We therefore focus in our analysis on East Germany for which rationing of childcare slots is not an issue.

The federal regulations ("Public Assistance for Children and Youth Act") define the goals of public childcare as follows: providing care and custody; education and learning; and developing social and noncognitive skills - all to further the welfare of children and their families. In practice, many different educational traditions (like Montessori, Waldorf etc.) exist side-byside; most common is the situation-oriented approach, a social pedagogy tradition that stresses flexible schedules, problem-solving and social skills through play, social interaction and informal learning in addition to age-specific activities (like a visit to the local zoo, for instance). This tradition contrasts with a school-oriented approach that focuses on teaching cognitive skills and certain basic knowledge (see Sohns, 2009 for a survey).

Publicly subsidized daycare in Germany is considered medium- to high-quality which is reflected both in expenditures per slot and in substantial regulation to secure quality standards. Expenditures for formal daycare of preschool children in Germany are above the OECD average (OECD 2006). The annual variable costs for a slot in formal childcare in Thuringia in 2005 was approximately 5,500 euros or about \$6,000 (Thüringer Ministerium für Soziales, Familie und Gesundheit 2009). ${ }^{6}$ Variable costs are much higher in facilities for children under the age of 2 (about 10,300 euros in 2005) and lower for children aged 3 to 6 (about 5,300 euros in 2005). These expenditures are substantially higher than those for the Head Start Program in the US, for instance, which costs around $\$ 5,000$ per year and slot for children from low-income families (Currie 2001). More than $50 \%$ of the costs of a childcare slot are covered by state subsidies while parents pay less than $20 \%$ of the costs on average.

Furthermore, detailed regulations by both the federal and state governments ensure strict

\footnotetext{
${ }^{6}$ In addition, East Germany invested about 14 million euros (in 2006) for building and renovating childcare infrastructure (Deutsches Jugendinstitut 2010). Taking the number of children under 6 in public daycare in East Germany of about 600,000, this implies an infrastructure cost of about 23,000 euros adding about 2,300 euros to the annual cost if written down over ten years. Hence, we obtain expenditures of about 7,800 euros per slot (or $\$ 8,900$ ). This number is likely to be an upper bound because some infrastructure investments apply to the care of older children after school.
} 
quality standards in each facility. Each childcare facility requires a permit which may be revoked if standards regarding group sizes, educational background of the staff, the physical environment and standards for hygiene and security are not met. Even private childcare providers comply with these federal and state regulations; otherwise, they would not obtain the generous public subsidies that cover a large share of the facility's variable costs. The local and state youth offices are responsible to monitor the requirements and impose sanctions in case of non-compliance (up to the point of closing a facility). Most importantly, state regulations require certain educational qualifications of the staff. Each childcare facility has to have at least one trained educator (defined as having either a vocational degree as an educator or a diploma in social pedagogy, both with a focus on early childhood education) for every 7 children from 0-2 years of age, for every 10 children from 2-3 years of age or for every 15 children from 4-6 years of age. The high quality of the staff is also reflected in their actual qualifications: $64 \%$ of all employees and $90 \%$ of the person heading a group have completed a vocational training as an educator, which involves a curriculum of two years at a vocational school together with practical training followed by one year of practical training (OECD 2006). Many of the head teachers have a diploma in social pedagogy or related subjects involving a curriculum of 3-4 years at a technical college. State regulations also cover group sizes and the physical space provided. While the maximum group size is 25 , the average group size in Thuringia was 6.5 for children under the age of 3 and 12.1 for children from 3-6 years of age in 2006 (Deutsches Jugendinstitut 2010). ${ }^{7}$

\subsection{The New Family Subsidy in Thuringia}

On July 1 of 2006, the government in one of the five East German states (Thuringia) introduced the home care subsidy for families with small children ("Betreuungsgeld"). Parents of 2 year-old children now receive a subsidy if their child does not attend a publicly subsidized daycare facility. The size of the subsidy increases with the number of dependent children in the household. ${ }^{8}$ First-born 2 year-old children receive 150 euros per month, roughly equivalent to the federal child benefit available to all families. ${ }^{9}$ Second- and third-born eligible children receive 200 and 250 euros per month, respectively. Fourth- and higher-order eligible children even receive 300 euros per month (see table 1). For families in Thuringia, the new subsidy contributes a non-trivial share to household income: on average, the subsidy is about $10 \%$ of the median

\footnotetext{
${ }^{7}$ Each facility also must provide at least 2.5 square meters of playing space per slot with extra space for sleeping and for children under the age of 2. Each daycare center also has to provide 10 square meters of outdoor playing area per slot.

${ }^{8}$ Dependent children are defined as children under the age of 18 ; if the child attends education full-time, the threshold extended to age 27 .

${ }^{9}$ The federal child benefit for families with up to three children was 154 euros per month and child in 2006; a family with at least four children would get 179 euros per month for the fourth and any additional child.
} 
disposable household income in our sample of East German families with at least one child under the age of three. As shown in table 1, this share is even larger for certain subgroups in the population. The subsidy contributes between $11 \%$ and $22 \%$ to disposable household income for single parents, for example. If the child attends for fewer hours, the facility receives an amount that is proportional to the hours attended; the rest of the subsidy payment goes to the responsible parent. If the eligible child is in public daycare full-time ( 45 hours per week), the full amount of the new subsidy goes to the childcare provider.

Table 1: The Home Care Subsidy in Thuringia

$\begin{aligned} & \text { Eligible 2-year-old is 1st child } \\ & \begin{array}{l}\text { Euros } \\ \text { per Month }\end{array}\end{aligned}$ Whole Sample $\begin{gathered}\text { Percent of Monthly Household Income } \\ \text { Low Education }\end{gathered}$
Eligible 2-year-old is 2nd child
Eligible 2-year-old is 3rd child

The new subsidy replaced an earlier child-raising allowance for parents of children between 24 and 30 months in Thuringia. ${ }^{10}$ Under the old policy, parents with a child between 2 and 2.5 years of age received a monthly subsidy of 300 euros if at least one adult worked less than 30 hours per week and the monthly household income was below a certain income threshold (1,375 euros for two-parent families and 1,125 euros for single parents). Higher-income households received a lower payment or no transfer at all. Hence, the old policy was means-tested (conditional on income) but paid independently of the parents' childcare choices. Under the new policy, all families with eligible children between age 2 and 3 receive the subsidy (independent of their income or labor supply), but the amount received by the parents now depends on the family's childcare choices. We discuss in Section 4 how the change from the old to the new subsidy affects family choices and provide additional supporting evidence in Section 7.3 below.

The introduction of the home care subsidy was part of a broader political campaign by the Conservatives, the dominant political party in Thuringia since unification, and became

\footnotetext{
${ }^{10}$ This childcare allowance extended a federal policy for all parents with children under the age of two with similar eligibility criteria, work requirements and income thresholds. In January of 2007, the federal government abolished the policy in favor of a generous parental subsidy ("Elterngeld") for families with newborn children. The parental subsidy is now paid for a maximum of 14 months (if both parents take time off sequentially to care for the child) and can be as high as 1,800 euros per month (depending on prior earnings).
} 
a core issue during the election campaign of 2004. Its conservative supporters wanted, first, to compensate parents who do not use public daycare (and hence do not benefit from the substantial government subsidies for publicly provided daycare). The second goal was a better allocation of state subsidies to municipalities and facilities. Prior to the new policy, subsidies were based on the number of slots offered, not according to the number of children actually attending. Given an excess supply of childcare slots and rising childcare costs over time, the new rule was supposed to reduce overall state expenditures on childcare.

Yet, the new policy was heavily disputed and faced strong opposition by the left and center parties, the union for education and research, social welfare groups and even members of the conservative party themselves. The main concern raised by opponents of the policy was that the new policy would reduce personnel, quality and possibly the number of public daycare centers. Even after the conservative government passed the new law in December of 2005, the political battle continued. A petition for a referendum against the new policy was launched which collected more than 23,000 signatures - many more than the 5,000 signatures needed for a ballot. Despite its popular support, the referendum never took place as it was ruled impermissible by the constitutional court because of an administrative loophole. ${ }^{11}$ The intense political battle between the major parties and among the electorate suggests that the average citizen in Thuringia had no strong preference for the policy. In particular, it does not support the notion that the average voter in Thuringia became systematically more conservative regarding female labor supply and childcare for very young children than the average voter in East Germany reducing concerns about an omitted variable explaining both the reform and changes in family choices.

\subsection{The Home Care Subsidy and the Supply of Public Daycare}

Our analysis below focuses on how families adjust their demand for childcare in response to the new policy. Yet, the reform might have also affected the supply side, for instance, by expanding capacity or reducing fees for eligible families. In that case, our estimates would identify a combination of responses on the demand and supply side. The available aggregate evidence however, suggests few supply side adjustments. The main reason there is no adjustment on the supply side is that most childcare facilities are non-profit organizations and do respond little to demand conditions. Table A1 in the Web Appendix shows that the number of childcare slots and

\footnotetext{
${ }^{11}$ Petitions for referendums can only be held if they affect less than $0.5 \%$ of the state budget in the current year. Yet, the new policy was much larger than that threshold. The state governor therefore filed a lawsuit against the petition at the state constitutional court in October of 2006. In December of 2007, the constitutional court ruled with 5 judges against 4 that the petition against the new family law was impermissible.
} 
of personnel in childcare facilities has not changed much between 2006 and 2010 (see also figure A1 in the Web Appendix). Furthermore, childcare slots exceed the number of attending children by on average $14 \%$ (see figure A2 in the Web Appendix). We also find no evidence that opening hours changed in response to the new law. If anything, the average number of hours children attend public daycare seems to have increased between 2006 and 2009 (Thüringer Ministerium für Soziales, Familie und Gesundheit 2009). Even when childcare spaces and opening hours remain constant, facilities might try to attract more eligible children in order to receive the new subsidy. Table A1 does however not show any increase in the share of children under the age of 3 or eligible 2 year-old children in the post-policy period.

Facilities could also try to increase childcare fees for other children in response to the reform. Fees are set by the provider subject to state and local legislation and respond very little to demand conditions (Thüringer Ministerium für Soziales, Familie und Gesundheit 2009). Prices vary mostly with family income and the number of siblings. Low-income households, for instance, pay no fees, while higher-income households may pay up to 260 euros per month and child. The 2006 reform fixed childcare fees in all facilities at their 2005 level until 2007. Existing city-level evidence (see table A1) shows that childcare prices, if anything, declined after 2007. Furthermore, available proxies for childcare quality, like the number of children per childminder, do not suggest any changes over our study period (see figure A3 in the Web Appendix).

Finally, no further changes in the legislation or regulation of publicly subsidized childcare facilities took place in Thuringia between 2006 and 2007. The only other change that the new family policy of 2006 introduced was that all 2 year-old children are now guaranteed a slot in a publicly subsidized childcare facility. Yet, this guarantee has little consequences in practice because of an excess supply of childcare slots in each county (see figure A2). In sum, the available evidence suggests that the new policy had few effects on the supply side and justifies our focus on eligible families and their children.

\section{Theoretical Considerations}

To understand how the home care subsidy affects the childcare and labor supply choices in eligible families, we need to distinguish two cases. The first case applies to families who had no plans of sending their eligible child to public daycare. For them, the home care subsidy is essentially windfall income. If the family relies on informal childcare, the income effect might reduce the demand for informal care and increase childcare provided exclusively at home. If the family provides childcare at home, the income effect is likely to have little effect as long as home care is perceived to be of superior quality than informal childcare. The pure income effect also 
tends to reduce parental labor supply as long as leisure or parental childcare are normal goods.

The second case applies to parents who, in the absence of the reform, would have sent their child to public daycare. For them, the home care subsidy increases the hourly price of public daycare as the family now pays an additional 150 euros per month for a full-time daycare slot. This price increase is substantial compared to the average daycare fee of 90 euros per month in Thuringia. At the same time, the price increase is fully compensated by the home care subsidy. Therefore, families that would use daycare full-time can still afford the same bundle of goods as prior to the policy. However, they might not choose to do so because public childcare has become more expensive relative to other childcare modes. We thus expect a decline in public daycare attendance among eligible children because the compensated price effect is non-positive. Families who use public childcare face a reduction in the parent's net return from work. In response, the responsible parent (in most cases, the mother) might reduce her labor supply, and possibly use the additional time to care for the child at home. Alternatively, mothers might not adjust their labor supply but switch from public daycare to informal childcare instead. Parents who send their child to public daycare part-time are a mix of the two cases just discussed. The family still faces an increase in the hourly price of daycare; at the same time, part of the subsidy goes to the family as windfall income.

How parental demand for informal and home care respond depends on both the income and substitution effect. The substitution effect should reduce public daycare attendance and may increase or decrease other childcare modes. Informal care by relatives or paid nannies declines if informal and public childcare are complements, for example, because working mothers need to combine both childcare arrangements to cover a full workday. Childcare exclusively at home in contrast should be a substitute for public daycare and hence increase after the reform. The income effect in contrast should favor high-quality care arrangements like parental care. In sum, we expect the subsidy to increase childcare at home, while informal care may go up or down.

Some parents whose earnings are low enough to be eligible for the old subsidy experience a somewhat different effect on their disposable income. The old subsidy is higher than the new subsidy if the family has up to three children; at the same time, the old subsidy is only paid until the child is 2.5 years old while the new subsidy is paid until the child turns 3. As such, the switch from the old to the new subsidy mostly implies a temporal shift in the subsidy. If parents can smooth income, this temporal shift should have little effect on childcare choices and labor supply. At the same time, the reform eliminates the restriction on working hours (as at least one parent had to work less than 30 hours per week under the old policy). Hence, we would expect that low-income and possibly single parents who were the primary beneficiary of 
the old subsidy may actually increase their working hours under the new policy.

What reform effects do we then expect on average? Prior to the reform, less than $50 \%$ of young children in East Germany (35\% of 1 year-old and $44 \%$ of 2 year-old children) attended public daycare, most of them not full-time. Therefore, most families experience an income effect which should increase childcare at home and possibly decrease labor supply. Informal childcare in turn declines as long as informal care is an inferior good or a complement to public daycare. Our empirical analysis below identifies the compensated price response for public daycare. In addition, we can identify the elasticity of other childcare choices and parental labor supply to the combined effect of windfall income and an increase in childcare costs. All are behavioral parameters of interest for researchers and policy makers alike.

\section{$5 \quad$ Data and Empirical Strategy}

\subsection{Socio-Economic Panel}

To analyze the effect of the new policy on childcare choices and short-run behavioral child outcomes, we use data from the Socio-Economic Panel (SOEP). The annual panel surveys around 12,000 households about their childcare choices, labor supply, household income and the demographic structure of households. We restrict the analysis to the roughly 3,000 households from East Germany (without East Berlin) since employment opportunities, income levels and childcare provisions differ substantially between East and West Germany. ${ }^{12}$ In 2010, an additional sample of families with young children was drawn which is very similar in structure and content to the main study. We combine both data sets for our analysis in order to increase the sample size of East German families with young children. To focus on the years around the policy change, we further restrict the data to the period from 2000 to 2010 . We include in our analysis all families in East Germany with at least one child aged 1 or $2 .{ }^{13}$ Below, we also investigate potential spillover effects of the new policy on older and younger siblings in households with an eligible child.

Each year, parents report whether their children attend public daycare, whether someone outside the household (e.g. relatives, friends, neighbors or a childminder) cares for the child

\footnotetext{
${ }^{12}$ Female labor supply rates and childcare utilization for children under the age of three, for instance, are substantially higher in East than in West Germany. We exclude East Berlin because labor supply and childcare provisions in the capital (combining East and West Berlin) are likely different from the rest of East Germany. A second reason to drop East Berlin is to keep our sample consistent across the two data sources as the Micro Census does not distinguish between East and West Berlin.

${ }^{13}$ Including families with at least one child eligible in the current or coming year, we identify the direct effect of the policy (for 2 year-old children) as well as anticipatory changes in childcare (for 1 year-old children). Our results are similar if we restrict the sample to eligible 2 year-old children (see table A6) though based on a smaller number of observations.
} 
or whether childcare is exclusively provided in the home by a member of the household (like parents, grandparents or older siblings) instead. Based on this information, we code a set of binary indicators for the childcare choices in each household. The first variable indicates if the child attends a public childcare facility (and is zero if the child does not attend any public childcare facility). The second indicator is equal to one if childcare is provided by relatives outside the household, friends, neighbors, a nanny or paid childminder. The variable is equal to zero if no such care arrangements are used. The final indicator is equal to one if the child is cared for exclusively in the home. The dependent variable is equal to zero if the household uses any care outside the home.

To analyze the effects on short-run child development, we make use of supplementary questions to mothers with newborn children. Since 2005, the questionnaire asks mothers with 2-3 years-old children to assess the health as well as her child's cognitive and non-cognitive skills. Specifically, the mother is asked to assess her child's motor skills, language ability, social skills and skills in daily activities based on the Vineland Adaptive Behavior Scale (VABS; see Sparrow et al. 2005). Each of the four categories is captured by five questions covering different aspects of the skill (which are described in more detail in the Web Appendix). For each question, the mother states whether the child is able, not able or only partially able to perform a particular task (for example, forming a sentence with multiple words or drawing recognizable figures). Based on the 20 items, we construct a score for each category (language, motor skills etc.) as well as a total score across all categories. In each category, we calculate the unweighted sum of the responses to the individual items. A larger score implies that a child is better able to perform the specific set of tasks. We then standardize the total score and each individual subcategory such that it has mean zero and a standard deviation of one in the sample of preschool children in East Germany.

While parental assessments are often the only source of information on the child's competencies especially when the child is very young, they may suffer from systematic biases. Caregivers may be positively or negatively biased in the perception of their children, may give socially desired answers, or may report certain behavior only because they are asked in the survey (e.g. Schwarz 1999). Yet, external validation studies of parent-reported data typically suggest they are informative about the skills they are intended to measure. There is also little evidence that any bias in parent-based reports is correlated with the socio-economic characteristics of parents (De Los Reyes and Kazdin 2005; Treutler and Epkins 2003). Furthermore, a recent validation of the VABS in the SOEP showed that maternal assessments are highly correlated with scores on an examiner-administered test of infant development (Sanders and Jungmann 2016). 
A final concern is that maternal assessments of their child is affected by the time a mother spends with the child. Mothers might become less critical, for instance, as they care for their child at home and observe the child's eating habits or language capacity throughout the day. In that case, a change in maternal assessments might be the result of changes in childcare arrangements induced by the home care subsidy - and not the consequence of an actual change in the child's competencies. In the absence of formal tests from developmental psychologists, we cannot test this concern directly. We can however, provide some indirect evidence that mere changes in perception are unlikely to explain our findings.

If maternal assessments mostly reflect the time spent with the child, they should not differ for children in informal or formal daycare holding hours of childcare outside the home constant. Table A2 in the Web Appendix shows estimates where the dependent variable is the total score of the Vineland Adaptive Behavior Scale. The key independent variable is the type of childcare mode used, and we control for socio-demographic characteristics (discussed in more detail in Section 5.3). Column (1) suggests that mothers assess their child more favorably if it attends high-quality public daycare than if it attends informal care. In column (2), we include an indicator equal to one if a child spends more time in public daycare than in informal care and zero otherwise. The results still show that maternal assessment is more favorable even if the child spends more time away from home in public daycare than in informal care. In the final specification in column (3), we include separate indicators for public daycare and informal care where the reference category is now care at home. If maternal assessment was positively correlated with time spent with the child, we should find negative effects for both indicators. However, we find the opposite result: while informal care has a small insignificant coefficient, the estimate for formal daycare is positive and remains statistically significant at the 10 percent level. ${ }^{14}$ Overall then, the evidence in table A2 supports the idea that maternal assessments indeed reflect the competencies of their child.

Table A3 in the Web Appendix shows descriptive statistics for our variables separately for children in the treatment state (Thuringia) and the rest of East Germany. ${ }^{15}$ There are a few differences in observable characteristics between treatment and control group in the pre-policy period like fewer single parents in Thuringia than in the rest of Germany, for example. This discrepancy is in part explained by the small samples of the SOEP (as we do not find these

\footnotetext{
${ }^{14}$ Furthermore, we find few meaningful correlations between the assessment and socio-economic characteristics of the parent or household. While both the age and gender of the child influences the assessment as expected, the only statistically significant correlation is that high-skilled mothers seem to assess their child somewhat more favorably than low- and medium-skilled mothers.

${ }^{15}$ The Web Appendix provides a more detailed description of our sample and the definition of all variables used in the empirical analysis.
} 
differences in the larger sample of the Micro Census). In the empirical strategy below, we discuss how we account for pre-policy differences in observables in our estimation.

\subsection{Micro Census}

To study labor supply and fertility responses, we employ the large samples of the German Micro Census. The Micro Census is an annual cross-sectional survey of $1 \%$ sample of the population covering about 820,000 individuals each year. The survey asks detailed questions about labor supply and household demographics. We restrict the analysis to households living in East Germany and to families with at least one 2 year-old child in the household.

The labor force participation variable is coded as one if a person works full- or part-time, is employed in a job for less than 400 euros per month (and hence exempt from social security contributions), works in a family business or is temporarily employed. The variable is also one if the parent is unemployed or on parental leave. The labor force participation variable is zero if the parent is out of the labor force and hence, not looking for work. Working hours if employed are coded as hours worked per week; full-time employment is an indicator equal to one if the parent works at least 30 hours per week. Finally, we also study fertility in households with at least one eligible child. The variable is equal to one if a child was born in the past 12 months in the household and zero otherwise.

Control variables are the age and gender of the child as well as the age, education, marital status and the foreign citizenship of the parent. We further control for household size, the total number of children, the number of preschool children and whether there is a child under the age of one in the household. Table A4 in the Web Appendix shows descriptive statistics for men and women with an eligible child in the Micro Census separately for Thuringia and the rest of East Germany. ${ }^{16}$ For the Micro Census, we find few pre-policy differences in characteristics though there seem to be more parents on unpaid parental leave and more married couples in the treatment group than in the control group.

\subsection{Empirical Strategy}

We estimate difference-in-difference model comparing childcare and labor supply choices of families with eligible children in Thuringia to the rest of East Germany before and after the policy change. The pre-policy period covers the years up to 2005 and the first six months of 2006. The post-policy period spans the time from July of 2006 to August of 2010. More

\footnotetext{
${ }^{16}$ Further details on the construction of the sample and individual variables can be found in the Web Appendix A.2.
} 
specifically, we estimate variants of the following model:

$$
Y_{i s t}=\alpha_{s}+\theta_{t}+\beta * \text { Eligible }_{i s}+\gamma * \text { After }_{t}+\delta * \text { Eligible }_{i s} * \text { After }_{t}+\lambda^{\prime} X_{i s t}+\varepsilon_{i s t}
$$

where $i$ represents the eligible child (for childcare and child skills), parent (for labor supply) or family (for fertility). The subscript $s$ denotes the state of residence and $t$ the year. The dependent variables $Y_{\text {ist }}$ are childcare choices (public daycare, informal daycare or home care), labor supply (employment, hours worked and full-time work), child competencies (motor, language or social skills and skills in daily activities) or fertility in households with eligible children.

The variable Eligible $_{i s}$ indicates whether a family has a child who is eligible for the home care subsidy in Thuringia and zero for families with children of the same age living in other East German states. After $t_{t}$ is equal to one in the post-policy period and zero before July 2006. The main parameter of interest is the coefficient on the interaction effect between the two indicator variables, $\delta$. The coefficient indicates how family choices change in Thuringia after the introduction of the new policy relative to choices of families in other East German states. Equation (1) also controls for a number of child, parent and household characteristics $X_{i s t}$ to account for existing observable differences between treatment and control groups. All estimations further include state $\left(\alpha_{s}\right)$ and year $\left(\theta_{t}\right)$ fixed effects as well as state-specific trends to adjust for time-invariant unobserved differences across states and aggregate or state-specific shocks. Finally, we include the current unemployment rate and the GDP growth rate in each state as well as both variables squared to control for changing economic conditions.

The effect of the home care subsidy $\delta$ in equation (1) is then identified from trend breaks in the behavior of parents with eligible children in Thuringia relative to the choices of parents with children of the same age in other East German states after the subsidy is introduced. The identifying assumption is that there are no differential trend breaks in Thuringia that coincide with the introduction of the new policy compared to the control states conditional on our control variables. Figure 1 traces the evolution of childcare choices (at the top) and labor supply (at the bottom) for the years before and after the reform (which is indicated by the black vertical line). The outcomes evolve similarly in treatment and control states prior to the reform. After the reform, there is an increase in home care and full-time work with few visible changes in public daycare or labor force participation.

To test the plausibility of our identifying assumption more systematically, we run a number of specification checks. First, we test for state-specific level differences and placebo reforms but fail to find meaningful differences between treatment and control states. Second, we use the group of slightly older children (3-5-year- old children) in a triple difference estimator to purge 
Figure 1: Childcare and Maternal Employment in Treatment and Control States
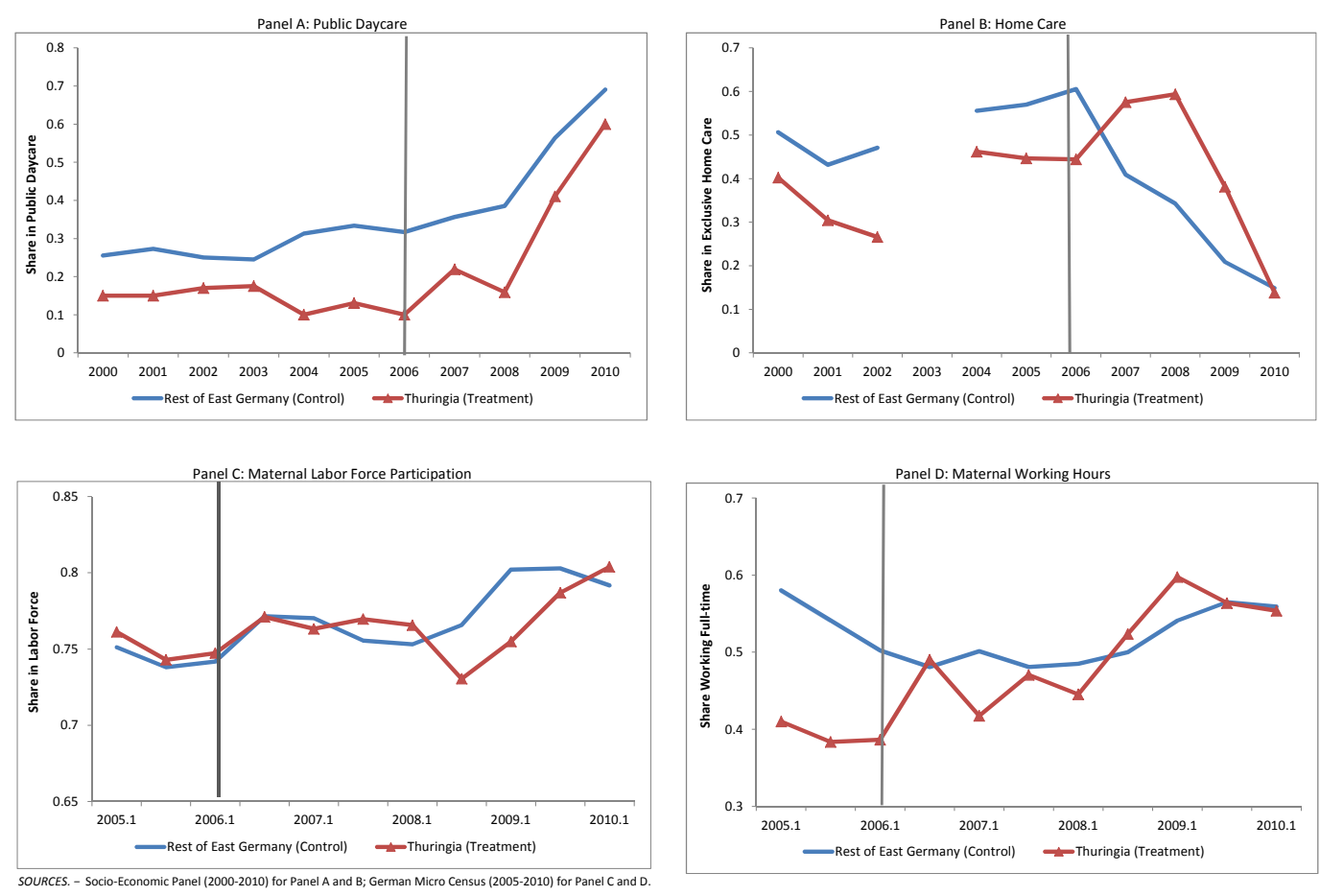

our estimates from state-specific shocks that are common across the group of preschool children. The results are very similar to our baseline estimates. Third, our set of control variables might not fully account for differences between treatment and control states. These differences would invalidate the parallel trend assumption if they also influence the dynamics of childcare choices or parental labor supply, for instance. To account for this possibility, we implement a semiparametric difference-in-differences estimator which uses re-weighting by the propensity score to adjust for pre-reform differences in observable characteristics. Finally, we augment equation (1) to account for shifts in state elections and other political changes but find results very close to our baseline. These specification checks are presented after our main results.

Another concern with our difference-in-difference analysis is the correct computation of standard errors. In the baseline, we report standard errors clustered at the state level to account for within-state dependence. As we only have one treatment state our standard errors might however, be biased. In Section 7.4 below, we report a number of alternative estimators for the variance-covariance matrix. 


\section{Empirical Results}

\subsection{Childcare Choices}

We use linear probability models to analyze the effect of the new subsidy childcare choices. The dependent variables are binary indicators whether the parents use public daycare, informal care or care for the child exclusively at home. Note that the indicators for public and informal care are not mutually exclusive as parents may combine formal and informal childcare. All specifications control for the child's age and gender, the age, education, marital status and foreign citizenship of the parent, household size and number of children in the household as well as aggregate state and time controls. The second specification in even columns also controls for the number of preschool children and the presence of infants (under the age of one) in the household. Table 2 reports the coefficient on the interaction effect between an indicator for the post-policy period and whether an eligible family lives in Thuringia (see equation (1)). The coefficients then represent changes in the likelihood of using a certain type of childcare.

Table 2: Effect of Home Care Subsidy on Childcare Choices

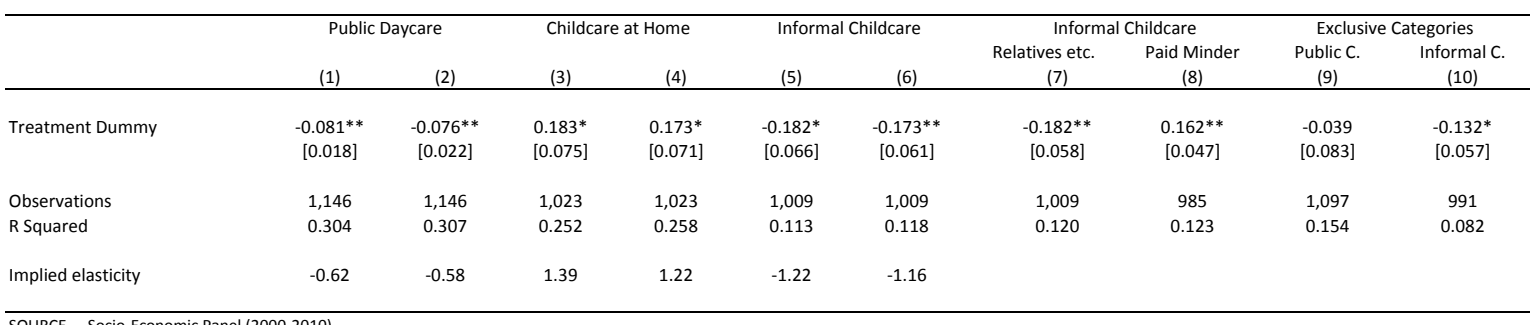

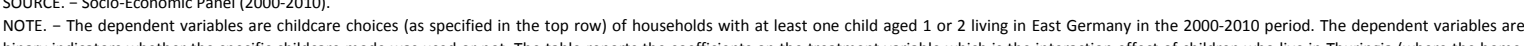
binary indicators whether the specific childcare mode was used or not. The table reports the coefficients on the treatment variable which is the interaction effect of children who live in Thuringia (where the home care subsidy was introduced) and an indicator for the post-policy period (after July of 2006). All specifications include as controls. age and sex of the child, age, marital status, foreign citizenship and education of the responsible parent, household size and number of children in the household. To control for aggregate economic conditions, we further include state unemployment and GDP growth rates (linear and squared terms),
state and year fixed effects as well as state-specific trends. Even columns also include controls for the number of preschool children and newborn children in the household. All standard errors are clustered at the state and year fix
state level.
$*$ p $<0.1$.

** $p<0.05$.

*** $p<0.01$.

Table 2 shows that attendance in formal daycare declines by about 8 percentage points or $23 \%$ (see columns (1) and (2) of table 2). ${ }^{17}$ At the same time, more children are exclusively cared for at home: the increase is with 18 percentage points or about $45 \%$ even larger than the decline in formal daycare (see columns (3) and (4) in table 2). The discrepancy between the two outcomes is explained by a substantial decline in informal care: after the reform, children are about 18 percentage points or $38 \%$ less likely to be cared for by relatives, friends, neighbors of private childminders (see columns (5) and (6) of table 2).

Based on the theoretical discussion in Section 4 above, there are two potential explanations

\footnotetext{
${ }^{17}$ The response on the extensive margin might underestimate the full effect of the subsidy as we have so far not said anything about adjustments on the intensive margin, the number of hours children attend formal daycare. Supplementary regressions (not reported) show a positive effect on full-time childcare attendance though the estimates are rather noisy.
} 
why informal care declines after the introduction of the home care subsidy. The first explanation is that formal and informal childcare are complements because parents combine formal and informal childcare to cover maternal working hours. In our data, about $60 \%$ of East German families with a 1-2 year-old child combine formal and informal care in the pre-reform period. As the implicit price of public daycare increases, both the demand for public and informal care would decrease if parents primarily substitute from combined formal and informal care to home care - and not from formal to more informal modes of care (as found in Norway or Sweden, for example; see Havnes and Mogstad, 2011a and Lundin et al., 2008). An alternative explanation is that there is a negative income effect for informal care. Parents who do not use public daycare spend the additional income to switch away from informal care and rely more on exclusive care at home. A negative income effect for informal care and a positive income effect for home care would be consistent with the idea that informal care is (or is perceived by parents to be) of lower quality than home care.

To better understand how important the two channels are, we first differentiate the type of informal care used. Our informal care variable combines care by neighbors, friends, relatives, paid childminders and nannies. Separate specifications for informal childcare (by friends, neighbors or other family members) and more formal (and typically paid) childcare (by childminders or nannies) are shown in columns (7) and (8). The results indicate that parents mostly substitute away from informal care in their social network which is more likely to be of low quality. In fact, the use of informal care by paid nannies and childminders actually increases after the reform. As a second piece of evidence, we estimate the same specification using exclusive categories for daycare and informal care. Here, we find that parents seem to reduce their exclusive demand for informal care, while the exclusive reliance on public daycare remains unchaged after the reform. These results suggest that the overall decline in public daycare (in columns (1) and (2) of table 2) is mostly explained by families who combine formal and informal childcare. The decline in informal care (in columns (5) and (6)) is in turn driven by parents who use the additional income from the subsidy to switch from informal care to home care.

We can use our estimates to calculate compensated elasticities of the demand for childcare with respect to childcare prices. Based on the response to the price increase (in column (2)), the full cost of public daycare (the subsidy amount plus parental fees) and the mean demand for daycare, we get an elasticity of around -0.6 (reported in the bottom row of table 2). ${ }^{18}$ Hence, the demand for public childcare does respond to prices conditional on availability. Furthermore,

\footnotetext{
${ }^{18}$ The mean subsidy amount is 184 euros while the mean price of daycare in the pre-reform period in the SOEP data is 91 euros. Together with public childcare attendance rates of $36 \%$ in the pre-reform period, we get: $-0.077 *(1.84+0.91) / 0.36=-0.593$.
} 
we can calculate a combined cross-price and income elasticity for informal care and exclusive home care. We find that both the demand for informal care with an elasticity of -1.2 and the demand for home care with an elasticity of 1.2-1.4 is highly responsive to the combined change in the price of formal daycare and income. ${ }^{19}$ Overall then, public subsidies in the formal childcare market have substantial effects on available substitutes and complements of public daycare. Does switching from formal and informal childcare to childcare in the home also mean that parents spend more time with their children? The available data in the GSOEP seem to suggest that. One question asks adults to report the number of hours they spend on childcare (though we do not know whether the additional time is spent with the eligible child). The reform seems to have increased the time spent with children by about 1-1.5 hours per day though the estimates are too noisy to reach statistical significance at conventional levels (not reported).

\subsection{Female Labor Supply}

We next turn to the question how female labor supply responds to the new policy. Table 3 shows linear difference-in-difference estimates of equation (1) where the dependent variables now represent different margins of labor supply. We start out with labor force participation in the year of eligibility, then analyze employment in periods after eligibility. We find that despite the declining demand for formal and informal childcare, there are no immediate effects on labor force participation in the overall sample. If anything, we see a slight decline in labor supply in the following year (by about 4 percentage points or $5 \%$ ) and two years later (by about 5 percentage points or 5\%) suggesting that mothers delay their re-entry into the labor market after the home care subsidy is introduced. ${ }^{20}$

We can use our estimates to calculate the employment response to childcare prices compensated by an income transfer: there is no immediate response of female labor supply to the policy. Even one or two years after eligibility, we find that employment is with -0.14 and -0.15 very inelastic; our estimated elasticities are however in line with earlier studies using quasiexperimental evidence (Baker et al. 2008; Blau and Tekin 2007). ${ }^{21}$ The absence of a strong

\footnotetext{
${ }^{19}$ The mean share of families using informal care in the pre-reform period is $41 \%$, while $39 \%$ of families care for their child at home. Taking the coefficient in column (4) and (6), we get $-0.173 *(1.84+0.91) / 0.411=-1.16$ for informal care and $0.173 *(1.84+0.91) / 0.39=1.22$ for home care.

${ }^{20}$ Recall that the dependent variable counts mothers as part of the labor force if they are on (unpaid) parental leave and hence, not actually working or looking for work. In Germany, parents can take up to 3 years of unpaid parental leave to care for their child and have the right to return to their original job within that period. To see whether changes into and out of parental leave drives the absence of an employment effect, we rerun the model of equation (1) using an indicator for parental leave (where the variable is zero if the mother works, is unemployed or out of the labor force). Mothers are more likely to be on unpaid parental leave after the reform though the effect does not reach statistical significance. Hence, the absence of an employment response in the current period cannot be explained by mothers remaining on unpaid parental leave longer under the new policy.

${ }^{21}$ One year after eligibility, we get:- $0.044 *(1.84+0.91) / 0.859=-0.141$; two years later, we have: -
} 
Table 3: Effect of Home Care Subsidy on Female Labor Supply

\begin{tabular}{|c|c|c|c|c|c|c|c|c|c|c|c|c|}
\hline & \multicolumn{2}{|c|}{$\begin{array}{l}\text { Labor Force Participation } \\
\text { (Year of Eligibility) }\end{array}$} & \multirow{2}{*}{\multicolumn{2}{|c|}{$\begin{array}{l}\text { Labor Force Participation } \\
\text { (Year after Eligibility) } \\
\text { (3) }\end{array}$}} & \multicolumn{2}{|c|}{$\begin{array}{l}\text { Labor Force Participation } \\
\text { (2 Years after Eligibility) }\end{array}$} & \multicolumn{2}{|c|}{$\begin{array}{l}\text { Hours Worked } \\
\text { (Year of Eligibility) }\end{array}$} & \multicolumn{2}{|c|}{$\begin{array}{l}\text { Full-time Employment } \\
\text { (Year of Eligibility) } \\
\begin{array}{ll}(9) & (10)\end{array}\end{array}$} & \multicolumn{2}{|c|}{$\begin{array}{c}\text { In School } \\
\text { (Year of Eligibility) }\end{array}$} \\
\hline & (1) & (2) & (3) & & (5) & (6) & (7) & $(8)$ & (9) & $(10)$ & (11) & (12) \\
\hline Treatment Dummy & $\begin{array}{c}0.010 \\
{[0.041]}\end{array}$ & $\begin{array}{l}-0.006 \\
{[0.047]}\end{array}$ & $\begin{array}{c}-0.022 \\
{[0.021]}\end{array}$ & $\begin{array}{l}-0.044^{*} \\
{[0.017]}\end{array}$ & $\begin{array}{l}-0.041 \\
{[0.025]}\end{array}$ & $\begin{array}{l}-0.048^{*} \\
{[0.020]}\end{array}$ & $\begin{array}{c}2.935 \\
{[1.827]}\end{array}$ & $\begin{array}{c}3.215 \\
{[1.868]}\end{array}$ & $\begin{array}{c}0.151 \\
{[0.079]}\end{array}$ & $\begin{array}{c}0.164 \\
{[0.083]}\end{array}$ & $\begin{array}{c}-0.054^{* * *} \\
{[0.009]}\end{array}$ & $\begin{array}{c}-0.056^{* * *} \\
{[0.009]}\end{array}$ \\
\hline $\begin{array}{l}\text { Observations } \\
\text { R Squared }\end{array}$ & 2,660 & 2,660 & 2,616 & 2,616 & 2,583 & 2,583 & 1,839 & $\begin{array}{l}1,839 \\
0,053\end{array}$ & 1,793 & 1,793 & 2,657 & 2,657 \\
\hline R Squared & 0.118 & 0.133 & 0.116 & 0.177 & 0.128 & 0.195 & 0.048 & 0.053 & 0.025 & 0.030 & 0.105 & 0.107 \\
\hline
\end{tabular}

SOURCE. - Micro Census (2005-2010).

NOTE. - The table reports the effect of the home care subsidy on female labor supply at the extensive and intensive margin as well as the probability of attending a (general or vocational) school or university. The sample is restricte to women aged 18-45 living in East Germany between 2005 and 2010 with at least one 2 years-old child in the household who have worked some time during their life. The treatment variable is the interaction effect of a parent with a two year-old child living in Thuringia (where the home care subsidy was introduced) and an indicator for the post-policy period (after July of 2006). All specifications include age, marital status, foreign citizenship and education of the parent as well as household size and number of children in the household. To control for aggregate economic conditions, we further include state unemployment and GDP growth rates (linear and squared terms), state and year fixed effects as well as state-specific trends. Even columns adjust for the number of preschool children and newborn children in the household. All standard errors are clustered at the state level.

$* p<0.1$.

$* * p<0.05$.

female labor supply response, despite substantial responses in childcare choices, suggests that many women whose child attends daycare do not work; or that working women have other childcare options available. In our sample, about $30 \%$ of mothers whose children attend public daycare are not employed in East Germany in the pre-reform period. The weak link between daycare arrangements and labor force attachment provides another explanation why we do not see strong substitution from formal to informal care as the price of formal daycare increases.

With respect to the intensive margin, there seems to be a positive effect on hours and full-time employment; yet, none of the coefficients reaches statistical significance (see columns (7)-(10) in table 3). The last two columns analyze whether mothers are more or less likely to attend school (in the four weeks prior to the interview) after the reform than comparable women in other East German states. The somewhat surprising result is that school attendance is lower among mothers with eligible children after the reform. This result is surprising because we would expect that higher income favors more educational investments. Yet, it is important to note that the variable combines attendance in high school, university and vocational school (which is part of an apprenticeship). In the first two cases, a person is considered out of the labor force; an apprentice in contrast, is considered employed. In supplementary regressions (not reported), we find that mothers who are employed are less likely to be in school. In contrast, school attendance slightly increases for mothers out of the labor force, which is consistent with the intuition that higher income favors full-time investments in education. As about threequarters of the women in school are employed, the overall effect of the reform on the propensity to attend school is negative however. In sum, the reform encourages full-time education, but reduces employment (and hence, attendance in vocational school).

$0.087^{*}(1.84+0.91) / 0.863=-0.153$. Given that these elasticities combine an income effect and an increase in childcare costs, the response to a price increase alone (without the windfall income to parents who do not send their child to public daycare) is likely to be even closer to zero than our estimated labor supply response in table 3 . 


\subsection{Fertility and Male Labor Supply}

The home care subsidy might also affect other family members through fertility decisions or paternal labor supply. In Section 7.2 below, we study possible consequences for older siblings of eligible children. Table 4 reports the results from estimating equation (1) where the dependent variables are now indicators for the presence of a newborn child in the household. In the first column, we estimate the overall effect for all households with a 2 year-old child. There is no statistically significant effect of the subsidy on the probability of having another child: while the coefficient is negative, the standard error is also large. As the subsidy increases with the number of dependent children (see table 1), families with two or more children might be more likely to consider another birth. To investigate this, we create separate indicators whether an eligible household has only one child or whether the household has additional children. The results in column (2) confirm that families with two or more children are more likely to have an additional child than families with only one child.

Table 4: Additional Adjustment Margins

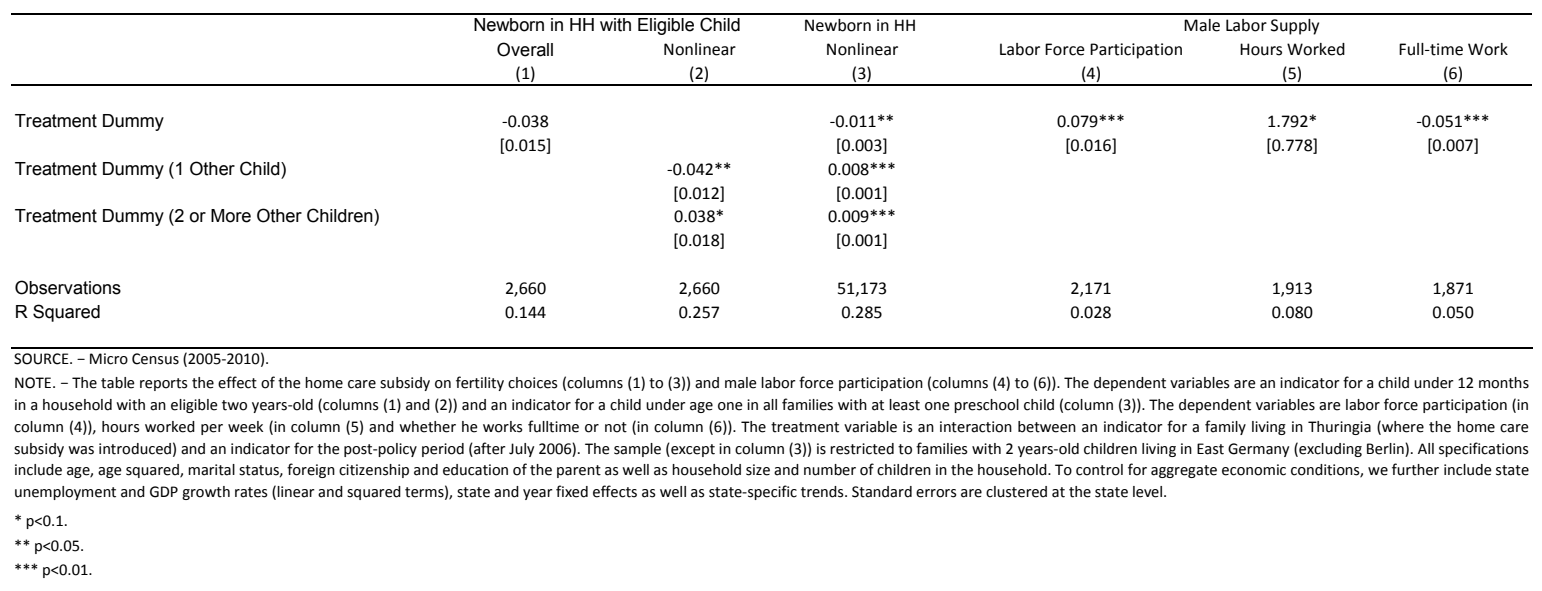

The home care subsidy might not only affect the fertility choices of families with an eligible child. All families with preschool children are potentially affected because they may receive the subsidy in the future. To check this, we use the sample of all East German families where the woman is in child-bearing age (18-45 years of age). We now include three treatment variables: whether the family living in Thuringia after the reform has no child yet, has one child or has two and more children. The triple interaction effect tells us whether the home care subsidy encourages some families to have their first child (or have it sooner) or whether it influences families with at least one child. The evidence in column (3) indicates that the home care subsidy seems to discourage the first birth, but has a negligible effect on families with one or more children. This result seems surprising at first because the demand for children should 
increase with income. Yet, an increase in public daycare prices might reduce the demand for children if parents invest more in the quality of the child after the reform (Becker 1960). Such an interpretation is in line with our evidence in table 2 that many parents switch from low-quality informal care to high-quality home care (and also spend more time with their child) after the reform. In contrast, it is difficult to explain the negative effect by a postponement of first birth. Higher childcare prices should reduce the net return of work (if parents rely on formal daycare to cover working hours). As a result, we should observe higher fertility as parents should plan for a birth (ceteris paribus) when the returns to work are low.

The right-hand side of table 4 shows the results for male labor force participation, working hours and full-time work. We find that employment and working hours actually increase somewhat in the full sample, while the share of men working full-time declines. These patterns suggest that it is mostly men not working or working less than full-time which increase their labor supply, possibly to compensate for a decline in spousal earnings.

Taken together, these results imply substantial adjustments in childcare choices and to a lesser extent in labor supply and fertility in response to the new home care subsidy. The consequences of these adjustments for welfare are not clear-cut as they depend, among other things, on the (relative) benefits of alternative childcare arrangements for child development. For example, we observe a shift from public daycare and informal care to home care. This shift might be beneficial for the average child if home care (by the parents) is of higher quality than public or informal childcare. It could be worse for a child's development if home care is of low quality, for example, because the child is left alone in the home. We therefore now turn to our evidence on the short-run consequences for child development.

\subsection{Child Outcomes}

To assess the consequences of the home care subsidy for short-run child development, we study a child's motor skills, language ability, social skills and skills in daily activities from the Vineland Adaptive Behavior Scale. We use the same estimation model in equation (1) and control variables as before. Our sample now consists of all 2-3 year-old children in East Germany which have either been eligible for treatment in the past or current year (or not at all if the family does not live in Thuringia). As in many other child development studies (see Almond and Currie 2011 for a survey), the sample size is with 434 observations rather small; the results should therefore be interpreted with caution.

The first column of table 5 reports the mean of the standardized scores in our sample; the mean is slightly above, but very close to zero. Column (2) and (3) show the result for the 
whole sample. We find little effect on the overall Vineland Scale. There is a (statistically weak) positive effect for social skills which is offset in the total score by small declines in motor skills. We next allow for differential effects of the home care subsidy on boys and girls. Columns (4) and (5) report the main effect while columns (6) and (7) show whether the effect for girls differs from that for boys. The surprising result is that the home care subsidy seems to benefit boys, but not girls. The subcategories suggest that boys seem to do better in terms of social skills and skills in daily activities while girls do not.

Table 5: Effect of the Home Care Subsidy on Child Outcomes

\begin{tabular}{|c|c|c|c|c|c|c|c|}
\hline & \multirow{2}{*}{$\begin{array}{c}\text { Mean } \\
(1)\end{array}$} & \multicolumn{2}{|c|}{ Boys and Girls } & \multicolumn{2}{|c|}{ Main Effect } & \multicolumn{2}{|c|}{ Differential Effect Girls } \\
\hline & & $(2)$ & (3) & $(4)$ & $(5)$ & (6) & (7) \\
\hline Vineland Adaptive Behavior & $\begin{array}{c}0.038 \\
{[0.990]}\end{array}$ & $\begin{array}{c}0.079 \\
{[0.081]}\end{array}$ & $\begin{array}{c}0.080 \\
{[0.068]}\end{array}$ & $\begin{array}{l}0.338^{*} \\
{[0.127]}\end{array}$ & $\begin{array}{c}0.325^{* *} \\
{[0.115]}\end{array}$ & $\begin{array}{c}-0.442^{* *} \\
{[0.150]}\end{array}$ & $\begin{array}{c}-0.484 * * \\
{[0.149]}\end{array}$ \\
\hline Social Skills & $\begin{array}{c}0.037 \\
{[0.962]}\end{array}$ & $\begin{array}{l}0.484^{*} \\
{[0.219]}\end{array}$ & $\begin{array}{c}0.411 \\
{[0.235]}\end{array}$ & $\begin{array}{c}1.326 * * * \\
{[0.275]}\end{array}$ & $\begin{array}{c}1.154^{* * *} \\
{[0.225]}\end{array}$ & $\begin{array}{c}-1.300 * * \\
{[0.288]}\end{array}$ & $\begin{array}{c}-1.237 * * * \\
{[0.271]}\end{array}$ \\
\hline Skills in Daily Activities & $\begin{array}{c}0.046 \\
{[0.985]}\end{array}$ & $\begin{array}{c}0.095 \\
{[0.150]}\end{array}$ & $\begin{array}{c}0.081 \\
{[0.132]}\end{array}$ & $\begin{array}{c}0.507^{* *} \\
{[0.135]}\end{array}$ & $\begin{array}{c}0.427 * * \\
{[0.132]}\end{array}$ & $\begin{array}{l}-0.684 * \\
{[0.248]}\end{array}$ & $\begin{array}{c}-0.710^{* *} \\
{[0.219]}\end{array}$ \\
\hline Language Skills & $\begin{array}{c}0.034 \\
{[0.964]}\end{array}$ & $\begin{array}{c}0.066 \\
{[0.151]}\end{array}$ & $\begin{array}{c}0.078 \\
{[0.166]}\end{array}$ & $\begin{array}{c}0.068 \\
{[0.170]}\end{array}$ & $\begin{array}{c}0.084 \\
{[0.163]}\end{array}$ & $\begin{array}{c}-0.020 \\
{[0.181]}\end{array}$ & $\begin{array}{c}-0.106 \\
{[0.176]}\end{array}$ \\
\hline
\end{tabular}

SOURCE. - Socio-Economic Panel (2003-2010).

NOTE. - The dependent variables are child outcomes (shown on the left) of 2-3 years-old children living in East Germany between 2003 and 2010. The data on noncognitive skills come from the supplementary "mother-child" and the "your child between age 2 and 3 " questionnaires, which ask additional questions of mothers with children born in 2003 or later $(\mathrm{N}=434)$. Mothers report whether a child is not able $(=0)$, partly able $(=1)$ or fully able $(=2)$ to perform a certain skill. The adapted Vineland Maturity Scale consists of 20 items in total where each of its four subcategories (social skills, motor skills, daily activities, language skills) contains 5 questions. All scores are standardized to mean 0 and standard deviation of 1 in the East German sample of preschool children. Larger scores mean that a child is better able to perform the specified skill. The table reports the coefficients on the treatment which is the interaction effect of 2-3 years-old children who live in Thuringia (where the home care subsidy was introduced) and an indicator for the post-policy period (after July of 2006). The coefficient is the change in the skill in terms of a standard deviation in the East German distribution. The first specification in columns (2) and (3) shows estimates for the whole sample. The second specification (in columns (4)-(7)) tests whether the effect varies for boys and girls: columns (4) and (5) show the main effect, while columns (6) and (7) report the differential effect for girls (by interacting the treatment variable with the child's gender). Columns (3), (5) and (7) add controls for the age structure of children in the household. All specifications include as controls: age and sex of the child; age, marital status, foreign citizenship and education of the parent, household size and number of children in the household. To adjust for aggregate economic conditions, we control for unemployment and GDP growth rates (linear and squared terms), state and year fixed effects as well as state-specific trends. All standard errors are clustered at the state level.

$* p<0.1$.

$* * p<0.05$.

$* * * p<0.01$.

How can we explain these large differences for boys and girls? There are three potential explanations (see also Baker and Milligan 2016 for a recent discussion). One potential explanation is that boys and girls have different production functions such that home care (parental time investments) has a larger benefit for boys than girls. There is some evidence in the psychological literature that maternal employment in the first years of life is associated with behavior problems for boys but not girls (e.g. Desai et al. 1989; Youngblade 2003). Yet, supplementary regressions of the development scores on attendance in daycare in the pre-policy period do not show any significant gender differences in the correlation between the type of childcare used and the Vineland score (not reported). While the sample size for the pre-policy period is very small $(\mathrm{N}=107)$, gender-specific benefits associated with home care do not seem to be the primary 
explanation for the differential responses.

An alternative explanation is that parents have different costs or preferences of investing in boys and girls. In both cases, we would expect that parents of eligible boys respond to the new subsidy in different ways than parents of girls. To investigate this channel, we re-estimate the childcare and labor supply responses from tables 2 and 3 where we now interact our treatment variables with the gender of the eligible child. The triple interaction effect (living in Thuringia in the post-policy period and being a girl) then picks up whether parents of eligible boys make different choices in response to the new policy compared to parents of eligible girls. Table A5 in the Web Appendix indeed shows differences in childcare choices: parents of boys are much more likely to switch from informal care to home care than parents of girls. To the extent that informal care is on average of lower quality and hence less beneficial for the development of the child, these results are in line with the benefits for boys documented in table 5 .

Overall, these results are consistent with parents facing gender-specific benefits or preferences for spending the subsidy. Investments in cognitive and non-cognitive skills might have higher monetary or non-monetary returns for boys, for example, because men are still more attached to the labor force than women. An alternative explanation is that parents enjoy spending time with their son more than with their daughter, for example, because they have a preference for sons (see Dahl and Moretti 2008 for the United States; and Ichino et al. 2014 for the United States, United Kingdom, Italy, and Sweden). ${ }^{22}$ Unfortunately, we cannot distinguish between these two explanations given the data available to us.

\subsection{Heterogeneity of Effects in the Population}

The average effect in eligible families we have analyzed so far could mask substantial heterogeneity in responses across population subgroups. We might expect, for example, a stronger response for economically disadvantaged families because the subsidy contributes a larger share to their disposable household income (see table 1). In addition, some households with low enough earnings were eligible for the old means-tested subsidy that was in place prior to 2006 . A third reason to analyze the heterogeneity in responses is that policy-makers are often more concerned about the economic self-sufficiency of vulnerable families.

To investigate treatment heterogeneity, we estimate variants of equation (1) where the treatment variable is now a triple interaction effect between an eligibility dummy (family with eligible children living in Thuringia), a post-policy dummy and an indicator for the respective popula-

\footnotetext{
${ }^{22}$ Consistent with our evidence in table A5, Ichino et al. (2014), for instance, show that mothers with first born sons are less likely to work and work fewer hours. They attribute this to increased marital stability when having a boy and thus a reduced need for additional income.
} 
tion subgroup: single mothers, low educated mothers and households in the bottom quintile of the (East German) income distribution. For the larger samples of the Micro Census, we also study immigrant families (where at least one parent is a non-EU citizen). Unfortunately, the small population of foreigners in East Germany (only about 3\% in our data) prevent us from a more detailed analysis of childcare choices for immigrants in the SOEP. Table 6 shows results for childcare choices and child outcomes (using the SOEP) on the left-hand side; results for female labor supply and fertility behavior (using the Micro Census) are reported on the right-hand side of the table. Note that the number of observations varies across subsamples because some households do not report their income or citizenship. All specifications include the same set of controls as in the baseline. The coefficients on the triple interaction effect then indicate whether families in the respective subsample react systematically different to the new subsidy compared to the overall sample of families.

Table 6: Heterogeneous Effects of the Home Care Subsidy

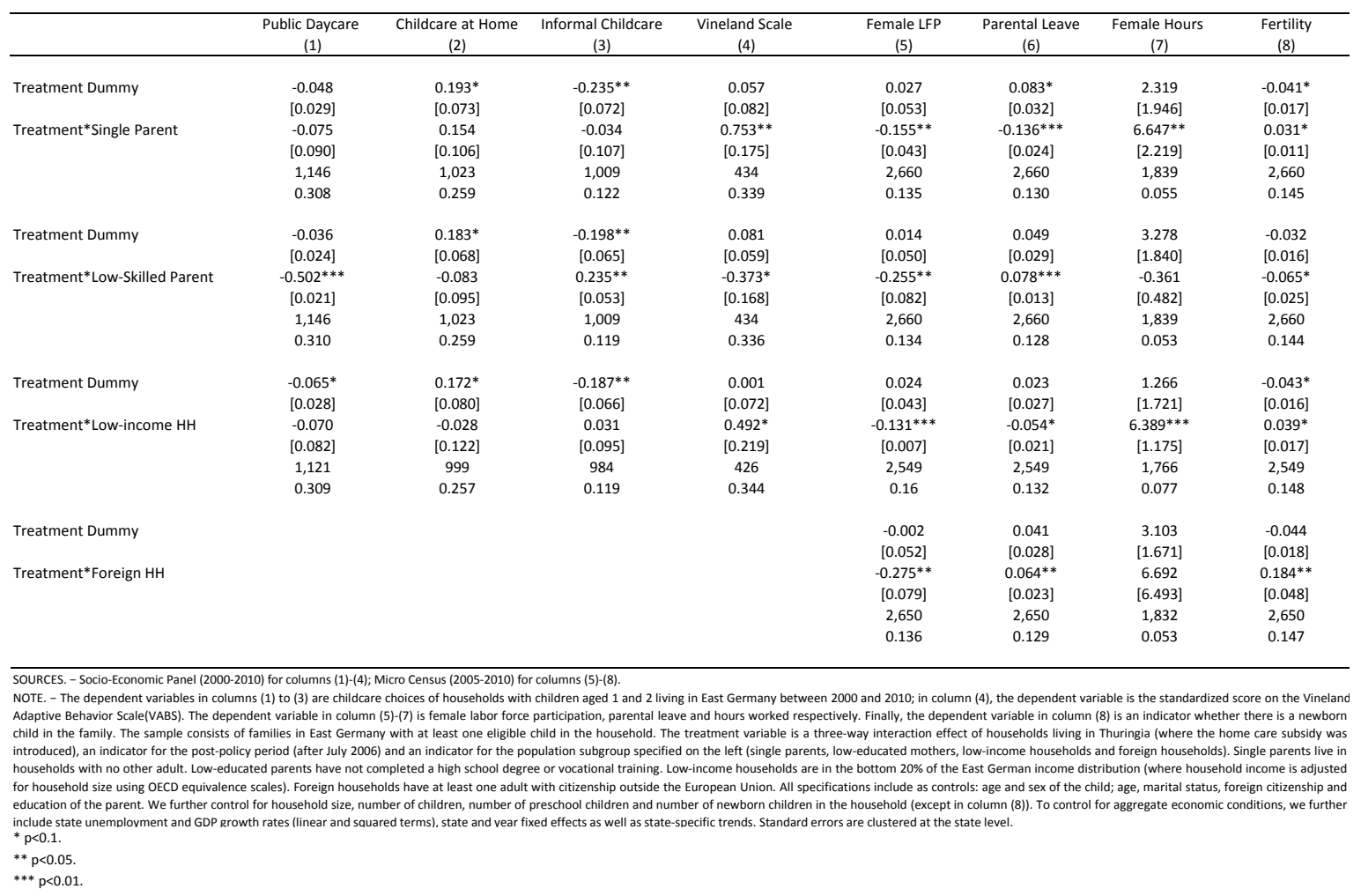

Table 6 shows several interesting patterns: for single parents and low-income households, changes in childcare arrangement are very similar to those in the overall sample. Yet, the observed switch from informal to home care benefits children from single or low-income households more than the average child. At the same time, we find a substantial decline in female employment among single and low-income mothers. That a decline in outside childcare is accompanied with a decline in employment among single mothers is not too surprising, given that single 
parents have fewer alternative sources of daycare available at home (by a spouse or partner). We do find, however, that single and low-income mothers who do work after the reform actually work more hours. ${ }^{23}$ We find a similar pattern for labor supply in non-EU households. Labor force participation rates decline while parental leave increases, suggesting that fewer immigrant mothers actually work in a job after the reform is implemented. For all three groups, we also find a positive effect on fertility. Given that the subsidy contributes a substantial share to the income of these families, it is not surprising that the fertility effects are stronger for single, low-income and foreign parents than in the overall sample.

The group for which we find somewhat different effects are low-skilled mothers without vocational training or high school degree. There is a strong decline in the demand for public daycare and an increase in informal childcare in the post-policy period. The switch to informal care becomes even stronger if we use an indicator for the exclusive use of informal childcare (where the indicator is zero if a child attends public daycare or home care). The shift away from professional daycare is also reflected in the VABS score: children of low-skilled mothers fare worse in terms of their cognitive and non-cognitive skills after the reform relative to children in states without the reform.

The response for informal care among low-skilled mothers is opposite the one for the whole sample in table 2 which suggests two potential explanations: first, low-skilled mothers consider formal and informal childcare as substitutes; or second, informal care is not an inferior good for low-skilled parents compared to home care. Supplementary regressions show that the exclusive use of informal childcare sharply increases among low-skilled mothers after the reform (not reported). This evidence supports the first interpretation that less-educated mothers consider formal and informal care as substitutes. We also find a negative effect on fertility for low-skilled mothers which is in line with evidence on the low-skilled population in the US (see Baughman and Dickert-Conlin 2009 for the EITC).

What does the evidence in table 6 imply for vulnerable families? The existing literature seems to come to the conclusion that high-quality public daycare benefits children, especially from low-income and less educated families (see Dustmann et al. 2015; Felfe and Lalive 2017 for Germany; Havnes and Mogstad 2011b for Norway; and Almond and Currie 2011 for a general survey and discussion of Head Start and the Perry Preschool Experiment, in particular). The observed shift away from public daycare among low-skilled families is then bad news for their children - a situation which we know is difficult to compensate later in life (Almond and Currie

\footnotetext{
${ }^{23}$ The increase in working hours could either be an increase in working hours among all working women or a selection effect where only mothers with long working hours remain in the labor market. We also find that children are more likely to attend public daycare for the full day after the reform (not reported).
} 
2011; Heckman 2006). In contrast, children from low-income families and single parents seem to benefit from the policy as the subsidy allows parents to switch from low-quality informal care to home care with positive effects on child development. At the same time, we find that female labor supply substantially declines for all subgroups which reduces their economic selfsufficiency. In sum, the evidence that the home care subsidy benefits vulnerable children and their families is mixed at best.

\section{Robustness Analysis and Standard Errors}

\subsection{Prior Trends in Treatment and Control States}

Key to our identification strategy is the parallel trend assumption between families with eligible children in Thuringia and families with children of the same age in the rest of East Germany. In addition to graphical inspection (see figure 1), we provide three alternative tests of this assumption. As a first step, we allow for flexible state-specific trends starting from no trend to a cubic state-specific trend. If there are differential trends across states, the inclusion of higherorder, state trends would change our estimates. Table 7 displays specifications with alternative state-specific trends; the estimates are remarkably similar to the baseline (shown in columns (2)-(4)). The only exception is the specification without any trend for some outcomes (in column (1)); yet, the difference is not statistically significant. Alternatively, column (5) allows the state-specific linear trend to vary before and after the reform. Note that this specification restrict time trends to be the same in all control states but allows for a trend break with the reform. We again find similar estimates though the coefficients become much noisier, possibly because the treatment-specific trend break absorbs a lot of the remaining variation.

As a second piece of evidence, we estimate placebo reforms where we shift the introduction of the home care subsidy in Thuringia to years between 2000 and 2005. The results for the indicator of the placebo reforms are shown in columns (6)-(9) of table 7. For childcare choices, our comparatively small sample in the SOEP produces estimates on the placebo reforms that jump around somewhat: for informal care and home care, we get significant estimates in 2004 which seems to be related to the break in the data in 2003 where we do not observe informal and home care (see also figure 1). It is, however, reassuring that there is again no differential trend in the pre-reform year. For public daycare, we get estimates that are never statistically different from zero. For labor supply, our sample starts only in 2005. We thus use the first 6 months in 2005 as our placebo reform. For labor force participation and hours worked, we get small negative coefficients which are not statistically significant. Overall then, the evidence from the 
Table 7: Specification Checks

\begin{tabular}{|c|c|c|c|c|c|c|c|c|c|c|}
\hline & \multicolumn{4}{|c|}{ State-Specific Trends } & $\begin{array}{c}\text { Treatment- } \\
\text { Specific Trend } \\
\text { (5) } \\
\end{array}$ & \multicolumn{4}{|c|}{ Placebo Reform: } & $\begin{array}{c}\text { Abadie's Semiparametric } \\
\text { Diff-in-Diff Estimator } \\
\text { (10) }\end{array}$ \\
\hline Childcare Attendance & $\begin{array}{c}0.002 \\
{[0.096]}\end{array}$ & $\begin{array}{l}-0.076^{* *} \\
{[0.022]}\end{array}$ & $\begin{array}{l}-0.076^{* *} \\
{[0.022]}\end{array}$ & $\begin{array}{c}-0.076^{* *} \\
{[0.022]}\end{array}$ & $\begin{array}{c}0.027 \\
{[0.054]}\end{array}$ & $\begin{array}{c}-0.064 \\
{[0.047]}\end{array}$ & $\begin{array}{c}0.063 \\
{[0.051]}\end{array}$ & $\begin{array}{c}0.099 \\
{[0.054]}\end{array}$ & $\begin{array}{c}0.040 \\
{[0.069]}\end{array}$ & $\begin{array}{c}-0.049 \\
{[0.093]}\end{array}$ \\
\hline Informal Childcare & $\begin{array}{l}-0.247^{*} \\
{[0.097]}\end{array}$ & $\begin{array}{l}-0.173^{* *} \\
{[0.061]}\end{array}$ & $\begin{array}{c}-0.173^{* *} \\
{[0.061]}\end{array}$ & $\begin{array}{l}-0.173^{* *} \\
{[0.061]}\end{array}$ & $\begin{array}{c}-0.108 \\
{[0.110]}\end{array}$ & $\begin{array}{c}0.102 \\
{[0.055]}\end{array}$ & $\begin{array}{c}0.010 \\
{[0.063]}\end{array}$ & $\begin{array}{c}-0.276^{* * *} \\
{[0.041]}\end{array}$ & $\begin{array}{c}0.065 \\
{[0.057]}\end{array}$ & $\begin{array}{c}-0.211^{* *} \\
{[0.112]}\end{array}$ \\
\hline Labor Force Participation & $\begin{array}{c}0.025 \\
{[0.034]}\end{array}$ & $\begin{array}{c}-0.006 \\
{[0.047]}\end{array}$ & $\begin{array}{c}-0.006 \\
{[0.047]}\end{array}$ & $\begin{array}{l}-0.006 \\
{[0.047]}\end{array}$ & $\begin{array}{c}0.021 \\
{[0.049]}\end{array}$ & & & & $\begin{array}{c}-0.013 \\
{[0.028]}\end{array}$ & $\begin{array}{c}0.153 \\
{[0.131]}\end{array}$ \\
\hline Hours Worked & $\begin{array}{l}5.305^{* *} \\
{[1.819]}\end{array}$ & $\begin{array}{c}3.215 \\
{[1.868]}\end{array}$ & $\begin{array}{c}3.217 \\
{[1.868]}\end{array}$ & $\begin{array}{c}3.219 \\
{[1.868]}\end{array}$ & $\begin{array}{c}3.592 \\
{[1.752]}\end{array}$ & & & & $\begin{array}{c}-0.619 \\
{[1.165]}\end{array}$ & $\begin{array}{c}8.483 \\
{[5.605]}\end{array}$ \\
\hline
\end{tabular}

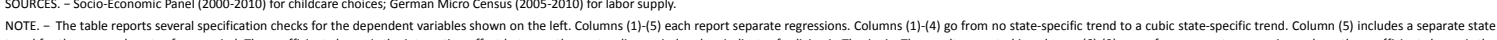
interaction effect between living in Thuringia and the prepolicy year indicted in the to row ("placebo reform"). The regression also includes an interaction effect between an indicator for Thuringia and an indicator for the post-policy period as well as all main effects in addition to the standard controls. The sample is restricted to families with 1-2 years-old children in East Germany for childcare choices and to families with 2 years-old children in East Germany for labor supply choices. For female labor supply, the placebo reform refers to the first 2 quarters in 2005 rather than the whole vear. Finally, columns (10) implements the semiparametric difference-in-differences estimator for repeated cross-sectional data by Abadie (2005). The propensity score is obtained by a series logit estimator and the difference-in-differences estimation is restricted to observations on the common support of the propensity score. Reported standard errors are adjusted for the estimation of the propensity score. Unless indicated otherwise, all specifications include state and year fixed effects

$* *$ p $<0.05$
$* * *$
$*<0.01$

placebo reforms support the interpretation that our baseline results for childcare choices and labor force participation are valid.

If different characteristics between treatment and control states are related to the dynamics of the outcome variables, the parallel trend assumption in the conventional difference-indifferences approach is violated. To address this concern in yet another way, we implement a semi-parametric difference-in-differences estimator which re-weighs the data to account for unbalanced observable characteristics (Abadie 2005). In a first step, a propensity score is estimated where the probability of treatment is related to observable characteristics. In the second step, the change in outcomes between the pre- and post-policy period is weighted by the ratio of propensity scores for the treated and untreated. Intuitively, the propensity score reduces the impact of observations in the control group that differ from the treatment group and increases the weight of control group observations that are similar to the treatment group in terms of their observable characteristics. We adapt the estimator to our setting with repeated crosssectional data (using Lemma 3.2 in Abadie 2005). The results for our outcome variables are shown in column (10) of table 7 . We again find similar results to the baseline: a shift away from informal care to care at home; a slight, though statistically insignificant decline in public daycare; and few immediate effects on female labor supply. Overall then, the evidence from flexible trends, placebo reforms and the semi-parametric difference-in-differences estimates support the inference drawn from our main results. 


\subsection{Triple Differences Approach}

Yet another way to account for potential trend differences across states is to find a suitable control group within the treatment state. Here we use households with slightly older preschool children (aged 3 to 5 ) in a triple differences approach. In table 8, we thus compare changes in childcare choices and labor supply between younger and older children in Thuringia before and after the reform relative to the rest of East Germany. The identifying assumption is now that childcare and labor supply choices of families with preschool children are subject to the same state-specific shocks or trends conditional on our baseline set of control variables. ${ }^{24}$

Table 8: The Effect of the Home Care Subsidy on Eligible Children and Older Siblings

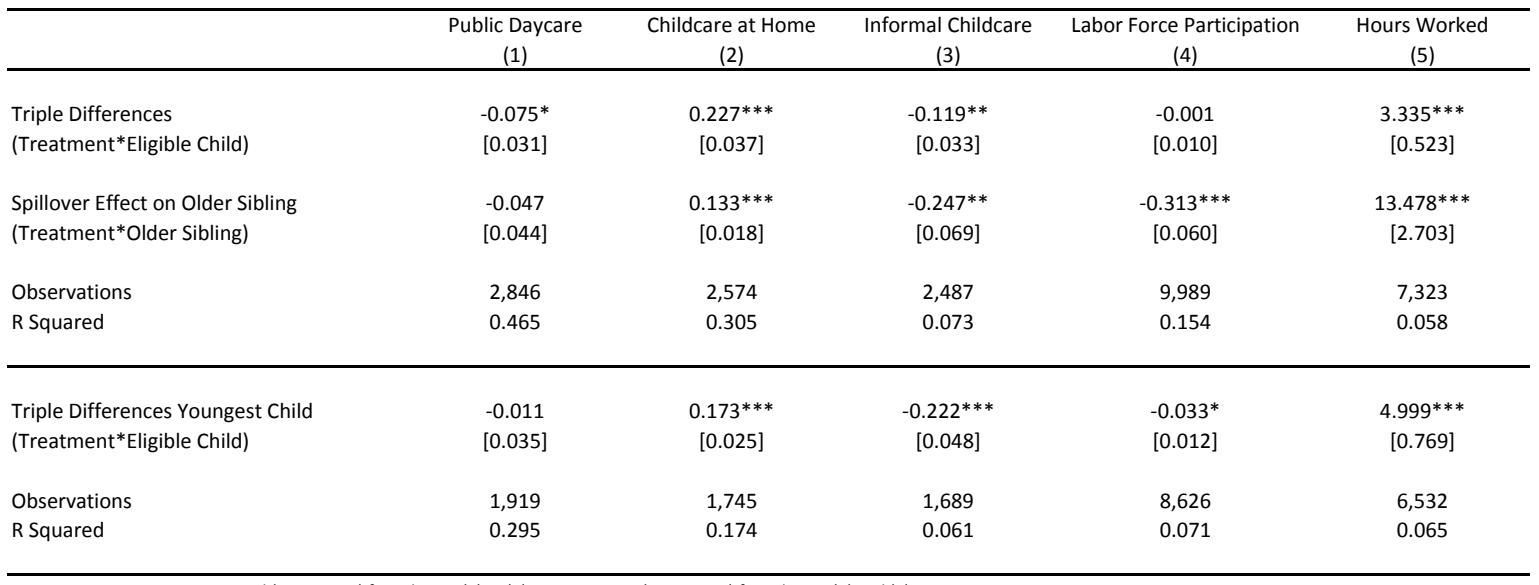

SOURCES. - Socio-Economic Panel (2000-2010) for columns (1) to (3); Micro Census (2005-2010) for columns (4) and (5).

NOTE. - The table reports the effect of the home care subsidy using older 3-5 years-old chilren as an additional control group (triple differences). The dependent variables are childcare and labor suppls choices indicated in the top row. The top panel contains two triple interactions: the first one is an indicator for living in Thuringia (where the home care subsidy was introduced), an indicator for the post. policy period (after July 2006) and an indicator whether the child is eligible for the home care subsidy ("Treatment*Eligible Child"). The second triple interaction effect is an indicator for living in Thuringia, the post-reform period and an indicator variable whether a 3-5 years-old child is the older sibling of an eligible child ("Treatment*older Sibling"). The reference category are 3-5 years-old children with no younger sibling eligible for the home care subsidy. The first triple interaction estimate shows the effect of the home care subsidy on eligible children; the second triple interaction effect identifies spillover effect on older siblings living in the same household as an eligible child. The bottom panel restricts the sample to children with no younger sibling in their household. The triple interaction effect here is for living in Thuringia, an indicator for the post-reform period and whether the child is eligible for the home care subsidy. All specifications include as controls: age and sex of the child; age, education, marital status and foreign citizenship of the parent. We further control for household size, number of children, number of preschool children and newborn children in the household. To control for aggregate economic conditions, we add state unemployment and GDP growth rates (linear and squared terms), state and year fixed effects as well as state-specific trends.

* p $<0.1$.

** $p<0.05$.

$* * * p<0.01$.

One concern with this alternative strategy is that some older children have siblings who are eligible for the subsidy. As the home care subsidy seems to affect the whole family and not just the eligible child, there might be spillover effects on the within-state control group. We tackle this concern in two different ways. Our first approach uses two indicators: the first indicator is equal to one if a child is an eligible child and zero if it is an older preschool child. The other indicator is equal to one if a child aged 3 to 5 is an older sibling and zero otherwise. The first triple interaction effect ("Treatment*Eligible Child") then identifies changes in childcare and maternal labor supply in families with eligible children relative to families with older preschool

\footnotetext{
${ }^{24}$ This assumption would be violated if, for instance, mothers of older preschool children were much more likely to work than mothers of eligible two year-old children. Yet, their labor force participation rates are actually surprisingly similar: $80 \%$ of mothers with two year-old children are in the labor force, while the share is $87 \%$ for mothers with 3-5 year-old children.
} 
children in Thuringia and relative to families with preschool children in the rest of East Germany. These estimates should be similar to the ones we obtained in our baseline estimation. The second interaction effect ("Treatment*Older Sibling") indicates whether families with older preschool children make different decisions in the treatment than the control states if there is an eligible child in the household. This estimate thus identifies the spillover effect of the subsidy on older siblings. Our second approach to implement the triple differences estimator is to focus on the sample of preschool children who have no younger sibling in the family. This sample restriction gets rid of the spillover effect. The triple interaction is now for living in Thuringia, an indicator for the post-policy period and whether the youngest child in the household is eligible for the subsidy.

Table 8 reveals two interesting patterns: first, the overall triple difference estimates (the first interaction effect in the top panel and the one in the bottom panel) show a pattern that is similar to those in tables 2 and 3 . We still find a switch away from public daycare and informal childcare and to more care in the home. At the same time, we find few adjustments in maternal employment and, if anything, an increase in working hours among employed women. Due to larger sample sizes, the standard errors are often smaller than in the baseline. The second interesting result is that the home care subsidy has substantial spillover effects on older siblings. Compared to 3-5 year-old children in ineligible families, older siblings are less likely to be in informal care (by about 25 percentage points) and more likely to be cared for at home (by about 13 percentage points). Parents who switch to home care for their 2 year-old child also reduce outside childcare for their other preschool children. We also find that mothers of 3-5 year-old children are less likely to be employed if there is an eligible child in the household; but if employed, mothers work longer hours.

\subsection{Additional Specification Checks}

Other confounding changes might bias our results. In the period under study, the federal government introduced a new parental leave program with generous payments to parents of newborn children born on or after January 1, 2007. The parent receives $67 \%$ of previous net earnings up to a maximum of 1,800 euros for up to 12 months after the birth (and up to 14 months if the other parent takes time off work for at least 2 months). If the paid parent leave affects all East German parents in a similar way, it will be absorbed by year fixed effects. To check for differential responses of families in the treatment state Thuringia, we add an indicator for the introduction of the federal parental subsidy to our specification. Web Appendix table A6 shows that this alternative specification has little effect on our estimates. The second 
check drops the neighboring state of Saxony who introduced a subsidy similar to the one in Thuringia in later years. Using this alternative set of control states has little effect on our estimates. Another concern could be that the electorate in Thuringia has become more socially conservative over time. Voters might support a new family policy and simultaneously expand care at home. To control for such simultaneous shifts in preferences, we include an indicator for the state election in Thuringia that occurred in June of 2004 (roughly two years prior to the reform). We find similar results though one coefficient loses statistical significance.

We further assess the robustness of our results to alternative definitions of the treatment and control group. Our baseline estimates for childcare choices in the SOEP uses the sample of families with 1-2 year-old children; in row (4), we restrict the sample to families with an eligible 2 year-old child. The coefficients are again similar to the baseline though statistically weaker because of the smaller sample size. Our next set of robustness checks uses alternative definitions of the treatment variable. The baseline specification uses simple dummy variables to define eligibility for the home care subsidy which does not account for the fact that the subsidy received varies across families with the number of dependent children. Row (5) uses the actual subsidy received to identify the treatment effect (see table 1$).{ }^{25}$ The coefficient on this treatment effect can thus be interpreted as percent changes for an additional 100 euros of subsidy payment. ${ }^{26}$

Finally, the home care subsidy replaced an older means-tested subsidy which was financially more generous than the new one when the child was less than 30 months old (see the discussion in Section 3.2 and 4). Low-income parents eligible under the old policy might therefore respond somewhat differently to the new policy, for example, because working hours were restricted under the old policy. Unfortunately, we cannot define the exact earnings threshold for the old policy with the income information available to us. To proxy eligibility for the old policy, we define our treatment variable equal to the old subsidy of 300 euros for low-income households in Thuringia (before July 2006) and zero for medium- and high-income parents. After July 2006, the treatment indicator is equal to the new subsidy for all eligible households in Thuringia. To cast the net a bit wider, we alternatively assign eligibility for the old subsidy to all low-income or low-skilled parents in Thuringia. The results (in row (6) and (7)), using the changes in subsidies from old to new policy, show that low-income (resp. low-income or low-skilled) parents mostly

\footnotetext{
${ }^{25}$ The subsidy is equal to 150 euros if the eligible child is the first-born in the family, and it is 200 euros for the second-born, 250 euros for the third-born, and 300 euros for the fourth- or higher-order child in the household. The treatment variable is zero for households in the pre-policy period and all households in the other East German states with at least one child between the ages of 1 and 2 .

${ }^{26}$ Households might base their decisions on the relative size of the subsidy instead of its actual amount. Using the interaction between the post-policy period and the subsidy divided by current household income yields results very similar in size to the baseline (not reported).
} 
switch from informal care to home care but also work more hours which is in line with the idea that parents may now choose their working hours optimally under the new policy (see also the evidence in table 6).

One might also worry about selective migration of eligible families to Thuringia in order to take advantage of the new subsidy. In that case, our estimates would not represent behavioral changes in eligible households but rather a change in the mix of eligible households residing in Thuringia. However, in- and outmigration especially for families with children under the age of 5 is extremely low (about 900 children per year compared to overall in-migration of roughly 16,500 per year). More importantly, migration into Thuringia does not increase after the introduction of the new family policy. While 890 families with children under the age of 5 moved to Thuringia per year between 2000 and 2005, the number was 896 between 2006 and 2010.

\subsection{Estimation of Standard Errors}

Our empirical strategy relies on policy changes in a single state which raises the question of how to compute correct standard errors. Our main results are based on standard errors that are clustered at the state level. However, this approach does not account for the small number of clusters. Table A7 reports alternative approaches to calculate standard errors. We rerun variants of equation (1) with standard errors clustered at the state-year level. Further, we include separate state clusters for the pre- and post-policy period to allow for breaks in the temporal dependence of the error term over time. Finally, clustering at the state level might also be too coarse to capture different local market conditions. We therefore use geographic information in the Micro Census to cluster roughly at the level of the county. The standard errors in table A7 are often larger than in our baseline such that some coefficients lose statistical significance. Finally, we implement a wild bootstrap procedure to estimate standard errors with state-dependent errors and a small number of clusters (Miller et al. 2008). This procedure generates $\mathrm{p}$ values similar to the baseline and hence confirms our qualitative conclusions.

\section{Conclusion}

This article studies the impact of childcare prices on childcare utilization, family labor supply and children's well-being. Empirically, we rely on the introduction of a home care subsidy in the East German state of Thuringia for identification. Our empirical results indicate four main lessons. First, all childcare choices respond to the new policy. Both public daycare 
and informal childcare decline, while childcare at home increases substantially. The decline in informal childcare is the consequence of two effects: about one-third of the decline is accounted for by the complementarity between formal and informal childcare. The remaining two-thirds of the effect are accounted for by parents who use the windfall income to substitute from lowquality informal care to exclusive care at home.

A second insight is that labor supply is not responsive to the policy even for parents with very young children (between the ages 1 and 2). In contrast to the general population, we find strong declines in labor force participation among single and low-skilled parents as well as low-income and non-EU households. Our third lesson is that boys benefit from the policy in terms of cognitive and non-cognitive skills while girls do not. The observed gender difference in child outcomes is consistent with differences in parental behavior: mothers of boys reduce their labor force participation and switch from informal to home care. Mothers of girls, in contrast, do not change their employment behavior or childcare choices. This differential response could either be explained by a higher utility of spending time with boys (e.g. because of a preference for sons), lower costs or higher monetary returns to investments in boys (e.g. in the future labor market). Fourth, our evidence shows that policies targeted at one family member affect all members of the household. We find that the subsidy affects fertility decisions and also generates substantial spillovers on older siblings. Evaluations of childcare subsidies or other types of family transfers therefore need to take a comprehensive view and consider responses along all margins within the family.

Finally, we can use our results to get a rough estimate of the fiscal costs associated with the new policy. For the calculation, we focus on the cost side and abstract from the revenue side (given that our labor supply responses are small). After the reform, the government pays a windfall subsidy to all families, even those not using public childcare. The cohort size of 2 year-old children in Thuringia is about 12,700 of which $54 \%$ do not attend public daycare. The average subsidy amount in our sample is 184 euros (since the subsidy increases in the birth order of the eligible child). As a consequence, the new policy requires additional expenditures of $1,261,900$ euros $(0.54 * 12700 * 184$ euros $)$ for the state government. At the same time, the government also saves money because some parents stop sending their child to daycare. Running costs in a public daycare facility are about 460 euros per month per slot of which parental fees cover about 90 euros (Thüringer Ministerium für Soziales, Familie und Gesundheit 2009). The remaining costs of 370 euros are mostly borne by the government. According to our estimates, the decline in public childcare is at most $23 \%$ which implies about 1,300 fewer children in public daycare. Hence, the government saves around 481,000 $(0.23 * 5715 * 370$ euros $)$ in the short run. 
Overall then, the new policy increases public expenditures of around 800,000 euros per year to the state budget. ${ }^{27}$

\section{References}

Abadie, A. (2005). Semiparametric difference-in-differences estimators. Review of Economic Studies, 72(1):1-19.

Almond, D. and Currie, J. (2011). Human capital development before age five. In Handbook of Labor Economics, vol. 4b, chapter 15, pages 1315-1486. Elsevier.

Anderson, P., Butcher, K. F., and Levine, P. B. (2003). Maternal employment and overweight children. Journal of Health Economics, 22(3):477-504.

Anderson, P. M. and Levine, P. B. (2000). Child care and mothers' employment decisions. In Card, D. and Blank, R., editors, Finding Jobs: Work and Welfare Reform. New York: Russell Sage.

Attanasio, O., Low, H., and Sanchez-Marcos, V. (2008). Explaining changes in female labour supply in a life-cycle model. American Economic Review, 98(4):1517-52.

Baker, M., Gruber, J., and Milligan, K. (2008). Universal childcare, maternal labor supply, and family well-being. Journal of Political Economy, 116(4):709-745.

Baker, M. and Milligan, K. (2010). Evidence from maternity leave expansions of the impact of maternal care on early child development. Journal of Human Resources, 45(1):1-32.

Baker, M. and Milligan, K. (2016). Boy-girl differences in parental time investments: Evidence from three countries. 10(4):399-441.

Baughman, R. and Dickert-Conlin, S. (2009). The Earned Income Tax Credit and fertility. Journal of Population Economics, 22(3):537-563.

Baum, C. W. (2003). Does early maternal employment harm child development? an analysis of the potential benefits of leave taking. Journal of Labor Economics, 2(2):409-448.

Becker, G. S. (1960). An economic analysis of fertility. In Demographic and Economic Change in Developed Countries, volume 11, pages 209-231. Princeton University Press.

\footnotetext{
${ }^{27}$ Additional savings might be incurred because we did not include investment costs in daycare facilities in the calculation; furthermore, the government could save additional funds because it now subsidizes the number of utilized childcare spaces (rather than the number of spaces provided). Given an average excess capacity of $14 \%$ on average, these additional savings might be substantial.
} 
Berger, L. M., Hill, J., and Waldfogel, J. (2005). Maternity leave, early maternal employment and child health and development in the US. Economic Journal, 115(501):F29-F47.

Berlinski, S., Galiani, S., and Gertler, P. (2009). The effect of pre-primary education on primary school performance. Journal of Public Economics, 93(1-2):219-234.

Bernal, R. and Keane, M. (2011). Child care choices and children's cognitive achievement: The case of single mothers. Journal of Labor Economics, 29(3):459-512.

Bettinger, E., Haegeland, T., and Rege, M. (2014). Home with mom: The effects of stayat-home parents on children's long-run educational outcomes. Journal of Labor Economics, $32(3): 443-467$.

Blau, D. M. and Currie, J. (2006). Pre-school, day care, and after-school care: Who's minding the kids? In Handbook of the Economics of Education. North-Holland: Elsevier.

Blau, D. M. and Tekin, E. (2007). The determinants and consequences of child care subsidies for single mothers in the USA. Journal of Population Economics, 20(4):719-741.

Blau, F. B. and Grossberg, A. J. (1992). Maternal labor supply and children's cognitive development. Review of Economics and Statistics, 74(3):474-81.

Boeri, T., editor (2005). Women at work: an economic perspective. Oxford University Press.

Brink, A., Nordblom, K., and Wahlberg, R. (2007). Maximum fee versus child benefit: A welfare analysis of Swedish child-care fee reform. International Tax and Public Finance, 14(4):457-480.

Carneiro, P., Loeken, K., and Salvanes, K. G. (2015). A flying start? Maternity leave benefits and long-run outcomes of children. Journal of Political Economy, 123(2):365-412.

Cascio, E. U. (2009). Maternal labor supply and the introduction of kindergartens into American public schools. Journal of Human Resources., 44(1):140-170.

Chiuri, M. C. (2000). Quality and demand of child care and female labour supply in Italy. Labour Economics, 14(1):97-118.

Connelly, R. (1992). The effect of child care costs on married women's labor force participation. Review of Economics and Statistics, 74(1):83-90.

Currie, J. (2001). Early childhood education programs. Journal of Economic Perspectives, $15(2): 213-238$. 
Currie, J. and Thomas, D. (1995). Does head start make a difference? American Economic Review, 85(3):341-364.

Currie, J. and Thomas, D. (1999). Does head start help Hispanic children? Journal of Public Economics, 74(2):235-262.

Dahl, G. and Moretti, E. (2008). The demand for sons. Review of Economic Studies, 75(4):10851120.

Datta-Gupta, N. and Simonsen, M. (2010). Non-cognitive child outcomes and universal high quality child care. Journal of Public Economics, 94(1-2):30-43.

De Los Reyes, A. and Kazdin, A. (2005). Informant discrepancies in the assessment of childhood psychopathology: A critical review, theoretical framework, and recommendations for further study. Psychological Bulletin, 131(4):483-509.

Desai, S., Chase-Lansdale, L. P., and Michael, R. T. (1989). Mother or market? effects of maternal employment on the intellectual ability of 4 year-old children. Demography, 26(4):545-61.

Deutsches Jugendinstitut (2006-2010). Zahlenspiegel - Kindertagesbetreuung im Spiegel der Statistik. Technical report, Deutsches Jugendinstitut München.

Dustmann, C., Raute, A., and Schönberg, U. (2015). Does universal child care matter? Evidence from a large expansion in pre-school education. Technical report, University College London.

Dustmann, C. and Schönberg, U. (2012). The effect of expansions in maternity leave coverage on children's long-term outcomes. American Economic Journal: Applied Economics, $4(3): 190-224$.

Felfe, C. and Lalive, R. (2017). Does early child care help or hinder children's development? Technical report, Univeristy of St. Gallen.

Fitzpatrick, M. D. (2010). Preschoolers enrolled and mothers at work? The effects of universal prekindergarten. Journal of Labor Economics, 28(1):51-85.

Gelbach, J. B. (2002). Public schooling for young children and maternal labor supply. American Economic Review, 92(1):307-322.

Goux, D. and Maurin, E. (2010). Public school availability for two year-olds and mothers' labour supply. Labour Economics, 17(6):951-962. 
Havnes, T. and Mogstad, M. (2011a). Money for nothing? Universal child care and maternal employment. Journal of Public Economics, 95(11-12):1455-1465.

Havnes, T. and Mogstad, M. (2011b). No child left behind: Universal child care and children's long- run outcomes. American Economic Journal: Applied Economics, 3(2):97-129.

Heckman, J. J. (1974). Effects of child-care programs on women's work effort. Journal of Political Economy, 82(2):136-163.

Heckman, J. J. (2006). Skill formation and the economics of investing in disadvantaged children. Science, 312(5782):1900-1902.

Herbst, C. M. (2013). The impact of non-parental child care on child development: Evidence from the summer participation dip. Journal of Public Economics, 105:86-105.

Ichino, A., Lindström, E.-A., and Viviano, E. (2014). Hidden consequences of a first-born boy for mothers. Economics Letters, 123(3):274-278.

James-Burdumy, S. (2005). The effect of maternal labor force participation on child development. Journal of Labor Ecoomics, 23(1):177-211.

Jaumotte, F. (2003). Female labour force participation: Past trends and main determinants in OECD countries. Working Paper 376, OECD Economics Department.

Kimmel, J. (1995). The effectiveness of child-care subsidies in encouraging the welfare-to-work transition of low-income single mothers. American Economic Review P\&SP, 85(2):271-275.

Kornstad, T. and Thoresen, T. (2007). A discrete choice model for labor supply and childcare. Journal of Population Economics, 20(4):781-803.

Kosonen, T. (2014). To work or not to work? The effect of child-care subsidies on the labour supply of parents. The B.E. Journal of Economic Analysis and Policy, 14(3):817-848.

Kottelenberg, M. J. and Lehrer, S. F. (2017). Targeted or universal childcare? Assessing heterogeneity in the effects of universal childcare. Journal of Labor Economics, 35.

Lefebvre, P. and Merrigan, P. (2008). Child-care policy and the labor supply of mothers with young children: A natural experiment from Canada. Journal of Labor Economics, 26(3):519548.

Lundin, D., Mörk, E., and Öckert, B. (2008). How far can reduced childcare prices push female labour supply? Labour Economics, 15(4):647-659. 
Miller, D. L., Cameron, C. A., and Gelbach, J. B. (2008). Bootstrap-based improvements for inference with clustered errors. Review of Economics and Statistics, 90(3):414-27.

Muehler, G. (2009). Consequences of mixed provision of child care - an overview on the German market. Technical report, Center for European Economic Research.

Naz, G. (2004). The impact of cash-benefit reform on parents' labour force participation. Journal of Population Economics, 17(2):369-383.

Nollenberger, N. and Rodriguez-Planas, N. (2015). Full-time universal childcare in a context of low maternal employment: Quasi-experimental evidence from Spain. Labour Economics, $36: 124-136$.

OECD (2006). Starting Strong II: Early Childhood Education and Care. Organisation of Economic Cooperation and Development: Paris.

Piketty, T. (2005). Impact de l'Allocation parentale d'education sur l'activite feminine et la fecondite en France, volume 4, chapter II, pages 79-109. INED.

Ribar, D. C. (1992). Child care and the labor supply of married women: Reduced form evidence. Journal of Human Resources, 27(1):134-165.

Ruhm, C. (2004). Parental employment and child cognitive development. Journal of Human Resources, 39(1):155-192.

Sanders, M. and Jungmann, T. (2016). How much can we trust maternal ratings of early child development in disadvantaged samples? Economics Letters, 141:73-76.

Schøne, P. (2004). Labour supply effects of a cash-for-care subsidy. Journal of Population Economics, 17(4):703-727.

Schwarz, N. (1999). Self-reports. How the questions shape the answers. American Psychologist, 54(2):93-105.

Socio-Economic Panel (2013). data for years 1984-2010, version 27. doi:10.5684/soep.v27.

Sohns, A. (2009). Pädagogische Konzepte in Kindertagesstätten. In Stein, R. and Orthmann Bless, D., editors, Basiswissen Sonderpädagogik. Baltmannsweiler: Schneider-Verlag.

Sparrow, S. S., Cicchetti, D. V., and Balla, D. A. (2005). Vineland Adaptive Behavior Scales: Survey Forms Manual. Circle Pines, MN: American Guidance Service. 
Thüringer Ministerium für Soziales, Familie und Gesundheit (2009). 1. Thüringer Familienbericht: Familien in Thüringen - eine gesamtgesellschaftliche Bestandsaufnahme. Report.

Treutler, C. M. and Epkins, C. C. (2003). Are discrepancies among child, mother, and father reports on children's behavior related to parents' psychological symptoms and aspects of parent-child relationships? Journal of Abnormal Child Psychology, 31(1):13-27.

Wagner, G. G., Frick, J. R., and Schupp, J. (2007). The German Socio-Economic Panel Study (SOEP) - scope, evolution and enhancements. Schmollers Jahrbuch, 127:139-169.

Waldfogel, J., Han, W.-J., and Brooks-Gunn, J. (2002). The effects of early maternal employment on child cognitive developmen. Demography, 39(2):369-92.

Youngblade, L. (2003). Peer and teacher ratings of third- and fourth-grade children's social behavior as a function of early maternal employment. Journal of Child Psychology and Psychiatry, 44(4):477-488. 